\title{
Seismic Performance of Deposit Slopes With Underlying Bedrock Before and After Reinforcement by Stabilising Piles
}

\section{Zhiliang Sun ( $\boldsymbol{D}$ zlsun@whrsm.ac.cn )}

Wuhan Institute of Rock and Soil Mechanics Chinese Academy of Sciences https://orcid.org/00000002-2330-7908

\section{Kong Lingwei}

Wuhan Institute of Rock and Soil Mechanics Chinese Academy of Sciences

\section{Bai Wei}

Wuhan Institute of Rock and Soil Mechanics Chinese Academy of Sciences

\section{Wang Yong}

Wuhan Institute of Rock and Soil Mechanics Chinese Academy of Sciences

\section{Research Article}

Keywords: rock-soil mixture deposit, slopes, stabilising piles, centrifuge models, seismic response

Posted Date: March 19th, 2021

DOI: https://doi.org/10.21203/rs.3.rs-327893/v1

License: (c) (i) This work is licensed under a Creative Commons Attribution 4.0 International License. Read Full License 
Seismic performance of deposit slopes with underlying bedrock before and after reinforcement by stabilising piles Sun Zhiliang ${ }^{\text {a, b, } * \text {, Kong Lingwei }}{ }^{\text {a, b }}$, Bai Wei ${ }^{\text {a, b }}$, Wang Yong ${ }^{\text {a, b }}$ a. State Key Laboratory of Geomechanics and Geotechnical Engineering, Institute of Rock and Soil Mechanics, Chinese Academy of Sciences, Wuhan, Hubei 430071, China

b. University of Chinese Academy of Sciences, Beijing, 100049, China

*Corresponding author.

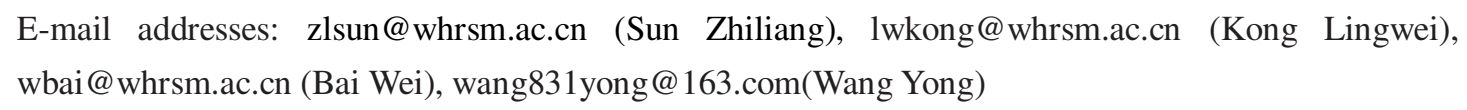

Abstract: The seismic performance of stabilising piles used to reinforce underlying bedrock in a deposit slope is a complex soil-structure interaction problem, on which there is limited design guidance on the optimum use of a single row of rock-socketed piles to reinforce such slopes. Two centrifuge shaking-table model tests at a geometric scale of 1:50 were conducted to ascertain the dynamic responses of the underlying bedrock deposit slopes without and with the use of stabilising piles during an earthquake. Multi-stage seismic waves with various peak accelerations were applied from the bottom of each model. Under seismic excitation, the differences in the response accelerations between the deposit and bedrock increase significantly with the increase in amplitude of the input seismic waves. The two are prone to uncoordinated movement, which leads to slope instability. Setting stabilising piles reduces the crest settlement and angular deformation and changes the natural frequency of the slope crest. The presence of the rock-socketed stabilising piles can bridge the uncoordinated movement of the bedrock and the overlying deposit to some extent. According to the mobilised pile bending moment, shear force, lateral pile-soil load distribution, and pile displacement, the dynamic response characteristics of stabilising piles under continuous multi-level seismic excitation were analysed. The resultant force arising from a distributed load increment on the piles caused by an earthquake is mainly concentrated in the upper part (the point of action of the resultant force is $1.54 \mathrm{~m}$ below the slope surface). With increases in the peak ground acceleration (PGA) of the input motion, the resistance of the bedrock in front of the stabilising piles increases; moreover, with the increase of PGA, the peak resistance under the bedrock surface of the stabilising piles gradually moves downwards. This finding indicates that the strong seismic motion significantly changes the embedded working state of the stabilising pile.

Key words: rock-soil mixture deposit; slopes; stabilising piles; centrifuge models; seismic response.

\section{Introduction}

Mixed rock and soil deposits mainly stem from landslide accumulation, residual accumulation, alluvial accumulation, etc. and are distributed widely as large-scale slopes in Sichuan Province, China (Huang and Li 2009; Ding et al. 2012). Deposit collapse and landslides account for a significant proportion of the disasters caused by the Wenchuan earthquake (Chigira et al. 2010; Cao et al. 2011; Yin et al. 2009). Theoretical analysis and research have shown that the surface amplification effect of a seismic slope is closely related to the impedance difference and wave velocity difference of near-surface geo-materials (Massey et al. 2017; Bourdeau et al. 2008; Del Gaudio and Wasowski 2011), such as the overlaying deposit (filling layer, colluvium layer, alluvium layer, etc.) on the bedrock, and the strong weathering 
layer covering the weak weathering layer, etc. (Strenk and Wartman 2011; Moor et al. 2011; Gischig et al. 2015). Deposit slopes with underlying bedrock are prone to secondary disasters such as dammed lakes and mudslides. In recent years, the construction of large-scale water conservancy projects, hydropower projects, and transportation hubs in south-western China have been undertaken and the risk of huge loss of life and property caused by earthquakes is increasing.

Stabilising piles are one of the most widely used engineering structures in landslide management because of the small disturbance of the surrounding geological environment, good support effect, and ease of construction (Carder and Temporal 2000; Li and Pei 2012; Lirer 2012; Li et al. 2016). On the other hand, the disaster investigation teams deployed after the Wenchuan earthquake found that stabilising piles generally had a good anti-seismic effect, but there are also a large number of stabilising piles that had overturned and even cracked and been broken (Wu et al. 2009). This suggests that the current understanding of the anti-seismic mechanism of stabilising piles is not yet clear: design and theory lag practical application and remain to be explored.

To understand the seismic strengthening mechanism of slope-stabilising piles, it is necessary to clarify the dynamic response of slopes under seismic action, the distribution of stabilising pile bending moment, and the distribution of earth pressures there on. At present, the research methods deployed include: on-site monitoring (Smethurst and Powrie 2007; Huang and Li 2009; Spence 2015; Bonilla 2002; Ou et al. 2019) and model testing (Yu et al. 2010; Al-Defae and Knappett 2014, 2015; Wang and Zhang 2014; Li et al. 2016; Ma et al. 2019; Huang et al. 2020). In recent years, there are more numerical simulation data available from studies of slopes reinforced by stabilising piles (Ellis et al.2010; Sharafi and Shams 2019; Won et al. 2005; Erfani Joorabchi et al. 2014; Kanagasabai et al. 2011; Kourkoulis et al. 2011), however, most of these studies are focussed on the behaviour of homogeneous slopes reinforced by stabilising piles.

The dynamic centrifuge model test can be used to simulate the prototype self-weight stress and replicate in-situ stress conditions. The test results can be used to verify the reliability of a numerical simulation; because of its operability and repeatability, it is an important technique in research into the effects of seismicity on slopes. From the perspective of the interaction between homogeneous sand and a pile, the former studies mainly focus on the seismic response characteristics of slope reinforced by stabilising piles (Al-Defae and Knappett 2014, 2015; Yu et al. 2010), the seismic response characteristics of inclined pile foundations ( $\mathrm{Li}$ et al. 2016), and the influence of liquefaction on pile foundations through centrifugal shaking-table model tests (Abdoun et al. 2003; Brandenberg et al. 2005; Knappett and Madabhushi 2009), inter alia. From the perspective of the interaction between homogeneous clay and a pile, Wang and Zhang (2014) conducted centrifuge model tests to study the seismic strengthening mechanism of stabilising piles by assessing the deformation profiles of slopes reinforced by stabilising piles under seismic load. Garala and Madabhushi (2019) studied the interaction between friction piles and soft clay under seismic load in centrifuge model tests. The aforementioned dynamic model tests of slope stabilising piles, and their mechanism of action, are mainly based on the dynamic response characteristics of sand, clay, and other homogeneous slopes; however, there are few studies on the dynamic response of a deposit slope with underlying bedrock and the working mechanism of the coarse-grained rock and soil mixture deposits, thus making it difficult to meet the needs of engineering practice.

Therefore, in this research, two sets of centrifuge shaking-table model tests were conducted to study the seismic response of a deposit slope with underlying bedrock with stabilising pile reinforcement and a similar unreinforced slope. The distributions of bending moments and lateral pile-soil load under 
continuous multi-level seismic loading were further explored. In the present work, the results are presented in terms of prototype-scale.

\section{Centrifuge testing programme}

\subsection{Test instrumentation}

The testing facilities included a ZJU-400 centrifuge and an electro-hydraulic servo-controlled shaking table developed by staff at Zhejiang University, China. It has an effective radius of $4.50 \mathrm{~m}$ and a capacity of $400 \mathrm{~g}$-tons. The size of the shaking table used in the tests is $800 \mathrm{~mm}$ in length and $600 \mathrm{~mm}$ in width. Its loading capacity is 0.5 ton. The seismic waves were applied to the model in the horizontal direction through the shaking table, which had a maximum acceleration capacity of $40 \mathrm{~g}$ (Chen et al. 2017; Zhou et al. 2018). The advantage of the centrifuge is that it allows the use of reduced-scale models to realise full-scale stress conditions. A rectangular rigid model box with internal dimensions of $770 \mathrm{~mm} \times 400 \mathrm{~mm} \times 530 \mathrm{~mm}$ (length $\times$ width $\times$ height) was used. A layer of soft plasticine plate with a thickness of $25 \mathrm{~mm}$ was sandwiched between the deposit and each end-wall. This set-up was used to absorb energy and reduce the intensity of reflected waves at the boundaries in the shaking direction (Sun et al. 2019).

\subsection{Similarity relationship and slope model design}

The similarity scale of the slope model is 50 (prototype size / model size $=50$ ), and the similar relationship of the centrifuge model is summarised in Table 1. In the present work, the model is somewhat idealised. The model is intended for use as a generic study of the seismic response mechanism rather than to represent a specific prototype. Fig.1 shows the schematic views of the unreinforced slope model ( $1^{\#}$ model), pile reinforced slope model ( $2^{\#}$ model), and model piles used for the primary test. The geometry of the unreinforced slope is identical to that of the pile-reinforced model.

Stabilising piles in the $2^{\#}$ model were made of aluminium alloy hollow square tube, with a side length of $30 \mathrm{~mm}$ and a thickness of $1.8 \mathrm{~mm}$. The pile spacing is $4 b$, namely $S=120 \mathrm{~mm}$. The parameters pertaining to the prototype stabilising pile are listed in Table 2. According to Kourkoulis et al. (2011, 2012), the pile embedment depth $L_{\mathrm{e}} \geq 0.7 H_{\mathrm{u}}$ ( $L_{\mathrm{e}}$ is the pile embedment length and $H_{\mathrm{u}}$ is the depth of the unstable soil layer) can guarantee working stability when the pile is embedded in a stronger substratum. In $2^{\#}$ model in Fig.1(b), $L_{\mathrm{e}} / H_{\mathrm{u}}$ is nearly 0.61 .

\subsection{Soil properties}

Deposit samples were collected from the Mianmao Highway line, Sichuan Province. The sampled material has a small fines content, a mean grain size $d_{50}$ of $3.3 \mathrm{~mm}$, a uniformity coefficient $C_{\mathrm{u}}$ of 9.95 , and a curvature coefficient $C_{\mathrm{c}}$ of 1.70 . The particle size distribution characteristics of the tested deposit are listed in Table 3. The minimum and maximum void ratios $\left(e_{\min }\right.$ and $\left.e_{\max }\right)$ are 1.466 and 2.102, respectively. The internal friction angle of the tested deposit is $41^{\circ}$ and its apparent cohesion is $4.8 \mathrm{kPa}$ at a relative density of 0.628 , and an initial dry density of $1.81 \mathrm{~g} / \mathrm{cm}^{3}$.

\subsection{Model preparation and test procedure}

The cemented material was used at a compacted density of $1.92 \mathrm{~g} / \mathrm{cm}^{3}$ when used to represent the bedrock. The mass percentage composition of the cemented material was silica sand: fines fraction of deposit: cement: water $=1: 1: 0.34: 0.27$, and rapid strengthening agents were added to $2 \%$ mass of the cement. Then the constructed bedrock model was cured for six days and the dynamic centrifuge tests were performed on day 7. The friction angle was $44^{\circ}$ and cohesion was $201 \mathrm{kPa}$ for the cemented material after a 7-day curing period as evinced by direct shear test data. The interface between the bedrock and deposit was generalised as two inclined planes and a horizontal plane, with inclined plane 
angles of $45^{\circ}$ and $20^{\circ}$, respectively (Figs 1 (a) and1(b)).

Pile bending moments were measured by seven pairs of strain gauges in a full bridge configuration mounted on the tube surface (Fig.1(c)): lateral pile-soil pressures were measured by four miniature transducers embedded in the pile. Pile strain gauges and miniature earth pressure transducers were calibrated before installation. After calibration and verification that all sensors were working, the model piles were then embedded in the bedrock.

When preparing the upper layer of the slope models, the deposit materials were compacted after placement in the model box using the controlled-volume method (Wang and Lin 2011) to a dry density of $1.81 \mathrm{~g} / \mathrm{cm}^{3}$. After placement of each layer, the deposit surface was smoothed with a soft brush and instruments were placed in their specific positions. Silicone oil was smeared over the sides of the rigid box to provide a lower friction coefficient at the interface with the walls.

The dynamic input was provided by the shaking table in the centrifuge. Multiple shaking events (El Centro motion) covering a wide range of peak ground accelerations(PGA) were applied to both the $1^{\#}$ and $2^{\#}$ models while in flight. The shaking was applied parallel to the long sides of the model container and orthogonal to the pile row. The peak values of the horizontal input acceleration in the shaking events were adjusted to nearly $0.05 g, 0.10 g, 0.20 g, 0.40 g$, and $0.20 g$ at prototype-scale (corresponding to $2.5 \mathrm{~g}, 5.0 \mathrm{~g}, 1.0 \mathrm{~g}, 2.0 \mathrm{~g}$, and $1.0 \mathrm{~g}$ at model-scale), which corresponded to seismic intensities of $6^{\circ}, 7^{\circ}$, $8^{\circ}, 9^{\circ}$, and $8^{\circ}$ based on the "Code for Seismic Design of Buildings" in China (GB 50011-2010). The time histories of input motions at instrument BA-0 are shown in Fig.2.

3 Acceleration response and crest settlement of slope

\subsection{Horizontal response acceleration}

The PGA amplification factor $S_{\mathrm{p}}$ is defined as the peak acceleration at a given depth normalised to the peak acceleration of the input motion) in the centrifuge tests as a function of normalised elevation $(h / H)$.

\section{(1) Unreinforced slope}

Fig.3 shows that, before reinforcement using stabilising piles, the PGA amplification factor of the slope increases substantially along the elevation direction and reaches the maximum at the crest of the slope. Under the continuous application of five levels of seismic load, the PGA amplification factor at the crest of the slope (A-3) has a mean average value of about 1.97, thus exacerbating the elevation amplification effect.

Moreover, at the same elevation on the slope, the PGA amplification factor of the deposit surface is greater than that of the bedrock surface, as shown in Fig.3(a), BA-0 $\rightarrow$ A-144 $\rightarrow$ A-179 and in Fig. 3(b), BA-0 $\rightarrow$ A-2 $\rightarrow$ A-6 $\rightarrow$ A-4. For example, at the height of $15.8 m$ (A-4, A-142, A-179), the horizontal acceleration amplification factor distribution from the inside of the slope to the surface of the slope is illustrated in Fig.4. The mean average acceleration amplification factors from within to the surface are 1.10, 1.06, and 1.27, respectively. The difference of the PGA amplification factors between deposit surface and bedrock surface shows typical surface amplification.

The strength difference of the bedrock and deposit also affects the seismic amplification effect. The shear strength of the deposit is lower than that of the bedrock, and the PGA amplification factors in that deposit are greater than those in bedrock. Acceleration sensors A-2, A-6, and A-4 are placed in the bedrock, as shown in Fig.3(b), and the measured amplification factors are close to 1.0.

Fig. 5 shows the transfer coefficient from A-0 to A-3: the components at frequencies of about 5 to $7 \mathrm{~Hz}$ are amplified when the seismic wave propagates from the bottom to the crest of the slope in the $1^{\#}$ model. 
(2) Slope reinforced by a discretely spaced pile row

Fig.6 shows the distribution of response accelerations along the slope elevation when reinforced by stabilising piles. It also shows increased amplification and surface amplification as compared in Figs 6(a) and 6(b). As shown in Fig.6(a), the average PGA amplification factor obtained from the crest measuring point (A-1) under continuous application of five levels of load is about 1.42, which is less than that obtained from A-3 (1.97) in Fig.4(a) when the slope is not reinforced by stabilising piles.

It is worth noting that the difference in PGA amplification factors between A-3 and A-144 is significant in the $2^{\#}$ model, as shown in Fig.6(a). The accelerations measured at A-144 and A-139, located below the stabilising piles, were significantly suppressed, while the acceleration measured at A-3 and A-7, located above the stabilising piles, increased slightly. A possible reason for this is that the stabilising piles lead to greater superposition of wave reflections in the passive zone under such seismic excitation, which generally shows that the amplification effect of horizontal response accelerations increases in front of the stabilising piles and decreases below them.

The horizontal acceleration amplification factor distribution from the interior of the slope to its surface at a height of $15.8 \mathrm{~m}$ in the $2^{\#}$ model during centrifuge testing is as shown in Fig.7. Akin to Fig.4, Fig.7 also shows the effect of surface amplification. The mean average acceleration amplification factorsunder each of the five levels of seismic load from the inside to the surface are 1.05 (A-4), 1.14 (A-179), and 1.29 (A-7), respectively.

Fig. 8 shows the amplitude ratios of the transfer function of the acceleration measured at A-1(slope crest) and A- 0 (bottom of the model box) in the $2^{\#}$ model during centrifuge testing. In addition to the frequency components at 5 to $7 \mathrm{~Hz}$, the frequency components at 15 to $17 \mathrm{~Hz}$ are also significantly amplified as the seismic wave propagates from the bottom to the crest, and the amplification is even greater than that of components at 5 to $7 \mathrm{~Hz}$.

(3) Comparison between unreinforced and reinforced slopes

Comparing Figs 5 and 8, the spectrum amplification effect of the input seismic wave is changed significantly after the landslide is reinforced by stabilising piles. This shows that the resonance frequency of the slope system is shifted from $5-7 \mathrm{~Hz}$ to $15-17 \mathrm{~Hz}$ after the stabilising piles has been installed.

To facilitate the analysis of the trend in the acceleration amplification effect inside the slope, the mean average value of the PGA amplification factors under multiple sequential ground motions was adopted at each measuring point, as shown in Fig.9.

From Fig.9(a), the mean average acceleration amplification factor in the upper part of the slope (A-179) is 1.326, which is greater than the magnification (A-4) at the same elevation within the slope (only slightly greater than 1), therefore, the different behaviours of the exterior and the interior of the slope will induce non-uniform movement. Qualitatively, the seismic waves that are transmitted from within the slope form superimposed reflection and interference effects on the superficial layer, resulting in an acceleration amplification factor of the slope surface that is larger than that within the slope. Comparing Fig.9(a) with Fig.9(b), it can be found that after the stabilising piles are installed, the acceleration amplification factor near the slope surface is reduced compared with that beforehand. Stabilising piles bridge the difference of acceleration response between the bedrock and deposit. The reason for the surface amplification effect can be explained as follows: part of the seismic energy is dissipated by damping during the propagation of seismic waves in the rock and soil mass, while the remaining energy is manifest as the seismic response of the rock and soil mass. The bedrock of the slope is harder than the upper part, so more energy is dissipated therein, and the dynamic response is 
smaller, while the surface soil mass of the slope is loose, the dynamic response is greater (Huang 2009; Massey et al. 2017). The inconsistency of the acceleration amplification effect will lead to an inconsistency of movement between the slope surface and the deep layer. The uncoordinated movement between the shallow soil and the rock in the slope produces a stripping tensile stress, and finally leads to the formation of a shallow surface landslide.

Fig.10 shows that the amplitude of the slope crest acceleration response spectrum (ARS) is decreased significantly after installing a single row of stabilising piles as reinforcement $(S / b=4)$ to the underlying bedrock deposit slope. In shaking event EQ4, the response spectrum values in the frequency range shown in Fig.10 are significantly reduced after the stabilising piles are installed, and the amplitude of the ARS decreases by 37\%. Overall, the larger the PGA of the input motion, the more significant the effect of the stabilising piles on the ARS peak reduction.

\subsection{Crest settlements}

The permanent crest settlements in each shaking event were monitored by laser displacement transducers LDS-1 and LDS-2 (Fig.1). The time-history curves of the slope crest settlements of each shaking event in the $1^{\#}$ and $2^{\#}$ models are shown in Fig. 11.

The permanent displacement of slope crest occurs only when the acceleration amplitude of the input ground motion reaches a threshold, and Newmark (1965) defined it as the critical acceleration. As shown in Fig.11, the crest settlements increased with increasing input amplitude of ground motions. In the shaking events EQ1 and EQ2, no obvious settlement occurred in the two models. When the input amplitude exceeded $0.2 g$ in shaking event EQ3, significant plastic deformation occurs in the slope crest as measured at LDS- 2 in both models. In shaking event EQ4 in the $1^{\#}$ model, $\Delta_{\mathrm{d} 1}=17.1 \mathrm{~mm}$ and $\Delta_{\mathrm{d} 2}=178.2 \mathrm{~mm}$, after stabilising piles are installed; $\Delta_{\mathrm{d} 1}=12.4 \mathrm{~mm}$ and $\Delta_{\mathrm{d} 2}=121.1 \mathrm{~mm}$ in the $2^{\#}$ model, and the crest settlements are reduced by approximately $27 \%$ and $32 \%$, respectively. The piles would be expected to increase Newmark's yield acceleration, as described by Al-Defae and Knappett (2013).

The distance $\Delta L$ between LDS-1 and LDS-2 is $3 \mathrm{~m}$ in the prototype and the angular rotation of the slope crest during the test is defined as follows: $\tan \Delta \theta=(\operatorname{LDS} 2-\mathrm{LDS} 1) / \Delta L$, where LDS2 and LDS1 refer to the values measured by using laser displacement transducers LDS-2 and LDS-1.The time-history curve of crest angular rotation is also shown in Fig.11. The final cumulative angular deformation in the $1^{\#}$ model is $0.06 \mathrm{rad}\left(3.4^{\circ}\right)$, and that in the $2^{\#}$ model is $0.0425 \mathrm{rad}\left(2.4^{\circ}\right)$. The change inangular rotationat the crest is almost the same as that in the crest settlement, which indicates that the crest settlement and the angular rotation will occur at the same time.

4 Response characteristics of stabilising piles under seismic load

\subsection{Horizontal displacement}

Fig.12 shows the time-history curve of the pile top horizontal displacement measured by laser displacement transducer LDS-3 in the centrifuge shaking table model test. The trend in pile top horizontal displacements in Fig.12 is akin to that in Fig.11: under a small input ground motion (EQ1, EQ2), there is almost no residual horizontal displacement at the pile top. In shaking event EQ3 $(\mathrm{PGA}=0.236 \mathrm{~g})$, the residual horizontal displacement of the pile top begins to occur, indicating that the stabilising piles begin to be pushed, so that the pile top starts to undergo horizontal residual deformation. Under the excitation of a strong earthquake $(\mathrm{EQ} 4, \mathrm{PGA}=0.421 \mathrm{~g}$ ), the pile top undergoes a significant horizontal displacement, in which the maximum instantaneous horizontal displacement reaches $15.8 \mathrm{~mm}$ and the residual horizontal displacement of the pile top is $6.7 \mathrm{~mm}$. This shows that the overlying deposits have a sliding, downwards trend, and the stabilising piles have begun to bend significantly. From EQ4 to EQ5, the incremental residual horizontal displacement of the pile top is 
minimal, suggesting that the previous vibration has enhanced the seismic resistance of the slope to some extent when the slope is subjected to a strong excitation first and then excited by a smaller earthquake.

Fig.13 shows the amplitude ratios of the transfer function of the acceleration measured at A-1079 (pile top) and A-0 (bottom of the model box) in the $2^{\#}$ model during centrifuge testing. Its distribution is similar to that in Fig.8. The difference is that the amplification factor of frequency components at 5 to 7 $\mathrm{Hz}$ at the top of stabilising piles is greater than that at the crest of the slope in the $2^{\#}$ model.

\subsection{Bending moment}

The typical response time-history curve of bending moments in the centrifuge model test (EQ4, S3) is shown in Fig.14. The residual bending moment increment $\Delta M_{\mathrm{r}}$ in each shaking event is defined as the difference between the beginning and the end of the response time-history curve of the bending moment. During the seismic loading process, the maximum dynamic bending moment $M_{\max }$ and the minimum dynamic bending moment $M_{\min }$ in each shaking event are taken as the difference between the beginning and the peak and trough of the time-history curve of the bending moment, respectively.

Fig.15 shows the time-history curves of bending moments measured by strain gauges on a stabilising pile under five continuous earthquake excitations (only $6 \mathrm{~s}$ of the time-history are taken in each case to show the variation in the bending moment). It can be seen from Fig. 15 that the bending moment measured at different points on the stabilising piles does not reach the maximum value at the same time. Taking EQ3 as an example (Fig.15(c)), the corresponding times to the peak signal amplitude are 109.91s, 109.91s, 109.92s, 109.93s, 109.95s, and 110.03s (S1-S7), and the corresponding times to the wave trough are 109.35s, 109.35s, 109.36s, 109.37s, 109.38s, 109.37 s, and 109.48s (S1-S7) at each strain gauge. It can be seen that the bending moment on the stabilising piles embedded in bedrock ( $\mathrm{S} 1$, $\mathrm{S} 2$, and S3) exhibits no phase difference, while there is a phase difference in the bending moment on the pile above the bedrock (S4, S5, S6, and S7), especially near the top of the pile (S7) where the time difference is about $0.1 \mathrm{~s}$. This is mainly due to the interaction between the stabilising piles and the deposit, and the onset of the effect of viscous damping which will be beneficial to the dissipation of earthquake energy.

The bending moment corresponding to the characteristic time shown in Fig.15 is extracted. Meanwhile, the maximum and minimum bending moments generated duringthe earthquake (due to the phase difference, the bending moment at each measurement point on the stabilizing pile cannot reach a maximum or minimum at the same time, which is called the maximum or minimum bending moment envelope) and the residual bending moment after the earthquake is extracted. After deducting the initial static bending moment generated by centripetal acceleration before the earthquake, the bending moment diagram along the pile height is plotted in Fig. 16.

It can be seen from Fig.16 that the dynamic bending moment corresponding to each characteristic time changes within the envelopes of the maximum and minimum dynamic bending moments. Therefore, the envelopes of maximum and minimum dynamic moments can be used as a basis to determine the design load in the seismic design of a stabilising pile. When the input seismic load is relatively small $(\mathrm{EQ} 1, \mathrm{PGA}=0.055 \mathrm{~g}$; $\mathrm{EQ} 2, \mathrm{PGA}=0.125)$, the positive and negative dynamic bending moments of the pile are quasi-symmetrically distributed, and the residual bending moment after the earthquake is small (and even negligible in EQ1) (Fig. 16 (a)).

After each shaking event (Figs 16(a)-(c)), the distribution of residual bending moment along the instrumented pile gradually increases from the slope surface to the bedrock surface, then decreases from the bedrock surface to the pile bottom, showing an outward convex shape, that is, the position of 
the maximum residual bending moment is near the bedrock surface, which is related to the earth pressure acting on the stabilising piles. After seismic loading at $\mathrm{PGA}=0.125 \mathrm{~g}$, the residual bending moment along the instrumented pile begins to increase, indicating that the overlying deposit begins to slide under the influence of the ground motion, which is consistent with the phenomenon whereby the aforementioned slope crest settlement starts to occur in shaking event EQ2 (Fig.11(b)).

In the first three shaking events $(\mathrm{EQ} 1, \mathrm{PGA}=0.055 g$; $\mathrm{EQ} 2, \mathrm{PGA}=0.125 g$; $\mathrm{EQ} 3, \mathrm{PGA}=0.236 g)$, the peak value of dynamic bending moment appears at measurement point $\mathrm{S} 3(H=5.5 \mathrm{~m})$, that is to say, it reaches its peak value near the bedrock-deposit interface: however, in EQ4 (PGA=0.421 $\mathrm{g}$ ), the positive maximum dynamic bending moment is still located at S3 at $t=159.19 \mathrm{~s}$, and the bending moment measured at S2 rapidly approaches that at S3 at $t=159.97 \mathrm{~s}$. At $t=161.84 \mathrm{~s}$, the positive bending moment at $\mathrm{S} 2$ has exceeded that at $\mathrm{S} 3$, that is, the positive maximum dynamic bending moment is located at $\mathrm{S} 2$ $(H=3.5 \mathrm{~m})$. The residual bending moment after earthquake EQ4 and the maximum positive dynamic bending in EQ5 are finally located at S2 $(H=3.5 \mathrm{~m})$ (Figs 16(d) and (e)). This shows that, under strong earthquake excitations, the part of the bedrock surface behind the stabilising piles begins to yield, the bearing layer of the bedrock socketed section moves down, as depicted in Fig.17, indicating that the strong seismic loading has significantly changed the stress state in the embedded section of the pile. It can be foreseen that, when the seismic load is further increased and the overturning moment generated by the landslide body exceeds the stabilising moment provided by the bearing capacity of the bedrock, the stabilising piles will undergo tilting-overturning failure.

It can be seen from Figs 16(d) and (e) that, if the model slope has experienced strong ground motion (e.g., EQ4, $\mathrm{PGA}=0.421 g$ ) beforehand, when the slope experiences a smaller earthquake motion (e.g., $\mathrm{EQ5}$, PGA $=0.236 g$ ) thereafter, the residual bending moment on the stabilising piles is almost unchanged. When continuous five-level excitation is applied, the maximum residual bending moment approaches $3250 \mathrm{kN} \cdot \mathrm{m}$. That is, the seismic load causes the overlying deposit to slide, and the permanent thrust generated on the stabilising piles increases the maximum bending moment by 3250 $\mathrm{kN} \cdot \mathrm{m}$.

\subsection{Lateral pile-soil load}

In the dynamic centripetal modelling tests, four earth pressure cells were placed on the stabilising pile above the bedrock surface. Fig.18 shows the incremental earth pressure measured after each shaking event. In addition, according to the differential relationship between moment $M$, shear force $Q$, and distributed load $q$ on the stabilising pile $\left(\frac{\mathrm{d} M}{\mathrm{~d} x}=Q, \frac{\mathrm{d} Q}{\mathrm{~d} x}=q\right)$, the distributed load $q$ on the stabilising pile after each shaking event can be roughly obtained $\left(\frac{\Delta M}{\Delta h}=\bar{Q}, \frac{\Delta \bar{Q}}{\Delta h}=\bar{q}\right.$, where $\Delta h$ is the distance between two adjacent moment gauges) from the residual moment diagram in Fig. 16. The comparison of distributed load increment obtained by moment strain gauge and earth pressure cell (from pressure integral to distributed load) on a stabilising pile after each shaking event is shown in Fig. 19 (the increment of distributed load in EQ1 is almost zero, so is not shown in Fig. 19 for clarity). It should be pointed out that the centrifuge model test gave values of pile-soil pressure on only one side surface of the pile, while the distributed load calculated from the bending moment is the pressure transmitted by the soil to the whole pile (four surfaces). There are differences between the two: Fig.19 shows that the distributions of the two are similar, but the values differ significantly when increasing the input PGA. To verify the rationality of the aforementioned differential method, Fig.20 shows the simplified distributed load increment above the slip surface after each shaking event according to Fig.19: the 
shape of the distributed load increment is the same, but the magnitude increases gradually with the increase of the input PGA.

The increment of distributed load in EQ1 is almost zero and in EQ5 it is equal to that in EQ4. It is noted that the distributed load increment generated by the seismic excitation in Fig.20 is negative near the slip surface, which indicates that the earth pressure in front of the pile is large, and the sliding force generated by the seismic excitation is mainly concentrated in the part above $3.5 \mathrm{~m}$ up the slip surface. It can be calculated that the point of action of the resultant force is $7.46 \mathrm{~m}$ above the slip surface. The point of action of the resultant force is $1.54 \mathrm{~m}$ below the slope surface, which indicates that the earthquake mainly causes shallow sliding of the deposit, resulting in distribution of the load increment in the upper part of the pile.

Taking the simplified distributed load generated by the earthquake in Fig.20 as the external load, the Mohr-Coulomb model was adopted for the bedrock (with the Young's modulus of bedrock set to 5.42 GPa, and Poisson's ratio to 0.30), and the stabilising pile (Table 2) was simulated as a Mindlin beam (Bathe 1982) with the help of PLAXIS 2D software (2015), the horizontal displacement, shear force, and bending moment on a stabilising pile after an earthquake can be obtained (Fig.21). In Fig.21(a), the horizontal displacements of pile in each shaking event are obtained by invoking Mindlin beam theory. The horizontal displacements of the pile top from EQ2 to EQ5 are 0.601mm, 2.08mm, 8.88mm, and $8.88 \mathrm{~mm}$, respectively. The pile top horizontal displacements measured by laser displacement transducer LDS-3 are $0.31 \mathrm{~mm}, 1.48 \mathrm{~mm}, 6.85 \mathrm{~mm}$, and $6.85 \mathrm{~mm}$, respectively. It can be found that the horizontal displacement of the pile tip obtained by use of Mindlin beam theory is slightly greater than that measured by laser displacement transducer, but the trend of the two is consistent. It can be seen from Figs 21(b) and (c) that, when the input PGA is small (EQ2), the pile shear force and bending moment obtained from Mindlin beam theory are in good agreement with the results obtained from the actual conversion of experimental bending moment data. With the increase of PGA (EQ3 and EQ4) of the input seismic wave, the shear force and bending moment on the pile in the bedrock obtained by Mindlin beam theory are much greater than those obtained experimentally; this is because the attenuation of the strength of the bedrock in front of the rock-socketed pile is not considered in the theoretical calculations. It is confirmed again that the resistance of the bedrock in front of the pile is redistributed under strong earthquake excitation (Fig.17). At the same time, it is verified that the distribution of pile-soil load estimated by use of the differential method is reasonable (Fig.20) in this case.

\section{Conclusion}

Under seismic excitation, the horizontal response accelerations in the two slopes show typical effects of elevation amplifications, surface amplification, and lithology. The arrangement of stabilising piles suppressed the downward trend in the motion of the overlying deposit. This results in a decrease in the difference between internal accelerations and external accelerations of the bedrock at the same elevation within the slope. A more obvious wave reflection superposition effect in the passive zone caused by the piles under ground shaking leads to the slope surface PGA amplification factor increasing in front of the piles and decreasing below the piles. In addition, through the transfer function between the slope bottom and the slope crest accelerations, it can be found that the installation of stabilising piles significantly amplified the 15 to $17 \mathrm{~Hz}$ frequency component.

The permanent settlements and angular rotation of the stabilising-pile-reinforced slope crest are reduced by about $30 \%$ compared with the unreinforced slope after five-stage seismic excitation is applied in centrifuge tests. The installed piles will increase the Newmark yield acceleration of the 
underlying bedrock deposit slope. The horizontal displacement at the top of the stabilising pile is closely related to the slope crest settlement and angular deformation.

The bending moment at each point on the pile does not reach its maximum simultaneously. There is a significant phase difference in the bending moment time-history curve pertaining to each measurement point, and the bending moment at the pile top lags that at the pile bottom. The short-term response amplitude of the dynamic bending moment is significantly larger than the corresponding post-earthquake permanent residual bending moment. The lateral pile-soil pressure above the bedrock gradually increases under continuous excitation imposed by five successive earthquakes. The point of action of the distributed load (when expressed as a single resultant force) is $7.46 \mathrm{~m}$ above the sliding surface, indicating that the earthquake mainly causes shallow sliding of the deposit to produce a residual sliding force. Under strong seismic excitation, the main bearing stratum of the pile-socketed bedrock section moves downwards, indicating that the stress state in that section of the pile embedded in the bedrock changes. In seismic design terms, the rock-socketed depth of each stabilising pile should be carefully selected in such deposit slopes with underlying bedrock.

\section{Acknowledgments}

The study is supported by the National Key R\&D Program of China (Grant No.2018YFC1505304), the National Natural Science Foundation of China (Grant Nos. 41702348, 51979269), and the Hubei Provincial Natural Science Foundation of China (Grant No. 2017CFB373).

\section{References}

Abdoun T, Dobry R, O'Rourke T, Goh S H (2003) Pile response to lateral spreads: Centrifuge modeling. Journal of Geotechnical and Geoenvironmental Engineering 129(10): 869-878

Al-Defae AH, Caucis K, Knappett JA (2013) Aftershocks and the whole-life seismic performance of granular slopes. Géotechnique 63(14): 1230-1244

Al-Defae AH, Knappett JA (2014) Centrifuge modeling of the seismic performance of pile-reinforced slopes. Journal of Geotechnical and Geoenvironmental Engineering 140(6): 04014014

Al-Defae AH, Knappett JA (2015) Newmark sliding block model for pile-reinforced slopes under earthquake loading. Soil Dynamics and Earthquake Engineering 75: 265-278

Bathe K J (1982) Finite element analysis in engineering analysis. Prentice-Hall, New Jersey

Brandenberg S J, Boulanger R W, Kutter B L, Chang D (2005) Behavior of pile foundations in laterally spreading ground during centrifuge tests. Journal of Geotechnical and Geoenvironmental Engineering 131(11): 1378-1391

Bonilia L F (2002) Borehole response studies at the Garner Valley Downhole Array, Southern California. Bulletin of the Seismological Society of America 92( 8): 3165-3179

Bourdeau C, Havenith H B (2008) Site effects modelling applied to the slope affected by the Suusamyr earthquake (Kyrgyzstan, 1992). Engineering Geology 97(3-4): 126-145

Cao ZZ, Youd TL, Yuan XM (2011) Gravelly soils that liquefied during 2008 Wenchuan, China earthquake, Ms=8.0. Soil Dynamics and Earthquake Engineering 31(8): 1132-1143

Carder DR, Temporal J (2000) A review of the use of spaced piles to stabilise embankment and cutting slopes. TRL Report 466, Transportation Research Laboratory, Berkshire, UK

Chen YM, Li JC, Yang CB, Zhu B, Zhan LT (2017) Centrifuge modeling of municipal solid waste landfill failures induced by rising water levels. Canadian Geotechnical Journal 54(12): 1739-1751

Chigira M, Wu XY, Inokuchi T, Wang GH (2010) Landslides induced by the 2008 Wenchuan 
earthquake, Sichuan, China. Geomorphology 118: 225-238

Del Gaudio V, Wasowski J (2011) Advances and problems in understanding the seismic response of potentially unstable slopes. Engineering Geology 122(1-2): 73-83

Ding Y, Dang C, Yuan GX, Wang QC (2012) Characteristics and remediation of a landslide complex triggered by the 2008 Wenchuan, China earthquake-case from Yingxiu near the earthquake epicenter. Environ Earth Sci 67:161-173

Ellis EA, Durrani IK, Reddish DJ (2010) Numerical modelling of discrete pile rows for slope stability and generic guidance for design. Géotechnique 60(3): 185-195

Erfani JA, Liang RY, Li L, Liu HL (2014) Yield acceleration and permanent displacement of a slope reinforced with a row of drilled shafts. Soil Dynamics and Earthquake Engineering 57: 68-77. doi:10.1016/j.soildyn.2013. 10.011

Garala KT, Madabhushi SPG (2019) Seismic behaviour of soft clay and its influence on the response of friction pile foundations. Bulletin of Earthquake Engineering 17:1919-1939. https://doi.org/10.1007/s10518-018-0508-4

GB (2010) Code for seismic design of buildings, 50011-2010. China Building Industry Press, Beijing (in Chinese)

Gischig V S, Eberhardt E, Moore J R, Hungr O (2015) On the seismic response of deep seated rock slope instabilities - insights from numerical modeling. Engineering Geology 193: 1-18

Huang RQ, Li WL (2009) Analysis of the geo-hazards triggered by the 12 May 2008 Wenchuan Earthquake, China. Bull Eng Geol Environ 68: 363-371

Huang Y, Xu X, Liu JJ, Mao W (2020) Centrifuge modeling of seismic response and failure mode of a slope reinforced by a pile-anchor structure. Soil Dynamics and Earthquake Engineering 131: 1-11. https://doi.org/10.1016/ j.soildyn.2020.106037

Kanagasabai S, Smethurst JA, Powrie W (2011) Three-dimensional numerical modelling of discrete piles used to stabilize landslides. Canadian Geotechnical Journal 48(9): 1393-1411. doi: 10.1139/t11-046

Knappett J A, Madabhushi S P G (2009) Influence of axial load on lateral pile response in liquefiable soils. Part I: physical modelling. Géotechnique, 59(7), 571-581. doi:10.1680/geot.8.009.3749

Kourkoulis R, Gelagoti F, Anastasopoulos I, Gazetas G (2011) Slope stabilizing piles and pile-groups: Parametric study and design insights. Journal of Geotechnical and Geoenvironmental Engineering 137(7): 663-677. doi:10.1061/(asce)gt.1943-5606.0000479

Kourkoulis R, Gelagoti F, Anastasopoulos I, Gazetas G (2012) Hybrid method for analysis and design of slope stabilizing piles. Journal of Geotechnical and Geoenvironmental Engineering 138(1): 1-14

Li CD, Wu J, Tang HM, Hu XL, Liu XW, Wang CQ, Liu T, Zhang YQ (2016) Model testing of the response of stabilizing piles in landslides with upper hard and lower weak bedrock. Engineering Geology 204: 65-76

Li X, Pei X, Gutierrez M, He SM (2012) Optimal location of piles in slope stabilization by limit analysis. Acta Geotechnica 7(3): 253-259

Li Z, Escoffier S, Kotronis P (2016) Centrifuge modeling of batter pile foundations under sinusoidal dynamic excitation. Bulletin of Earthquake Engineering 14(3): 673-697

Lirer S (2012) Landslide stabilizing piles: Experimental evidences and numerical interpretation. Engineering Geology 149-150: 70-77

Ma N, Wu HG, Ma HM, Wu XY, Wang GH (2019) Examining dynamic soil pressures and the effectiveness of different pile structures inside reinforced slopes using shaking table tests. Soil 
Massey C, Della Pasqua F, Holden C, Kaiser A, Richards L, Wartman J, McSaveney MJ, Archibald G, Yetton M, Janku L (2017) Rock slope response to strong earthquake shaking. Landslides 14(1): 249-268. doi:10.1007/s10346-016-0684-8

Moore JR, Gischig VS, Burjanek J, Loew S, Fah D (2011) Site effects in unstable rock slopes: dynamic behavior of the Randa instability (Switzerland). Bulletin Seismological Society America 101(6): 3110-3116

Newmark N M (1965) Effects of earthquakes on dams and embankments. Géotechnique 15(2): 139-160

Ou J F, Luo Y H, Wang Y S, Zhu XM, Zhang YY (2019) Analysis of response characteristics of slope ground motion based on environmental noise and seismic data: A case study of Lushan Renjia slope. Journal of Mountain Science 37( 3) : 382-391. (in Chinese)

PLAXIS 2D (2015) Reference manual, Last version 2015.2.19890.4979. Delft, Netherlands: Delft University of Technology

Sharafi H, Shams Maleki Y (2019) Evaluation of the lateral displacements of a sandy slope reinforced by a row of floating piles: A numerical-experimental approach. Soil Dynamics and Earthquake Engineering 122: 148-170

Smethurst JA, Powrie W (2007) Monitoring and analysis of the bending behaviour of discrete piles used to stabilise a railway embankment. Géotechnique 57(8): 663-677

Spence R (2015) The full-scale laboratory: the practice of post-earthquake reconnaissance missions and their contribution to earthquake engineering. Bull Earthquake Eng 13:1581-1585. doi: $10.1007 / \mathrm{s} 10518-015-9751-0$

Strenk P M, Wartman J (2011) Uncertainty in seismic slope deformation model predictions. Engineering Geology 122(1-2): 61-72

Sun ZL, Kong LW, Guo AG, Xu GF, Bai Wei (2019) Experimental and numerical investigations of the seismic response of a rock-soil mixture deposit slope. Environ Earth Sci 78(24): 716. doi:10.1007/ s12665-019-8717-y

Wang KL, Lin ML (2011) Initiation and displacement of landslide induced by earthquake-A study of shaking table model slope test. Engineering Geology 122(1-2):106-114

Wang LP, Zhang G (2014) Centrifuge model test study on pile reinforcement behavior of cohesive soil slopes under earthquake conditions. Landslides 11(2): 213-223

Won J, You K, Jeong S, Kim S (2005) Coupled effects in stability analysis of pile-slope systems. Comput Geotech 32(4): 304-315

Wu Y, He SM, Li XP (2009) Failure mechanism of anti-slide pile under seismic wave. Journal of Sichuan University: Engineering Science 41(3): 284-288. (in Chinese)

Yin YP, Wang FW, Sun P (2009) Landslide hazards triggered by the 2008 Wenchuan earthquake, Sichuan, China. Landslides 6(2):139-152

Yu Y, Deng L, Sun X, Lü H (2010) Centrifuge modeling of dynamic behavior of pile-reinforced slopes during earthquakes. Journal of Central South University of Technology 17(5):1070-1078. doi:10.1007/s11771-010-0599-9

Zhou YG, Sun ZB, Chen YM (2018) Zhejiang University benchmark centrifuge test for LEAP-GWU-2015 and liquefaction responses of a sloping ground. Soil Dynamics and Earthquake Engineering 113: 698-713 
Figures
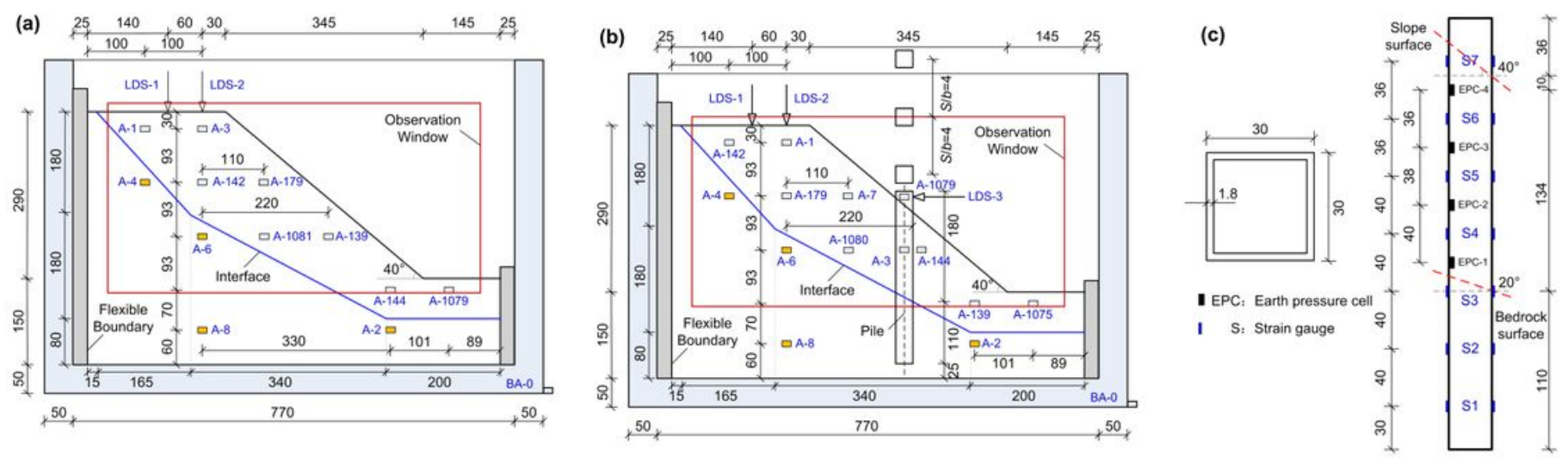

Figure 1

Layout of model slope and instrumentation at model-scale. a 1\#model. b 2\#model. c Layout of earth pressure cells and strain gauges on a model pile (unit: $\mathrm{mm}$ )

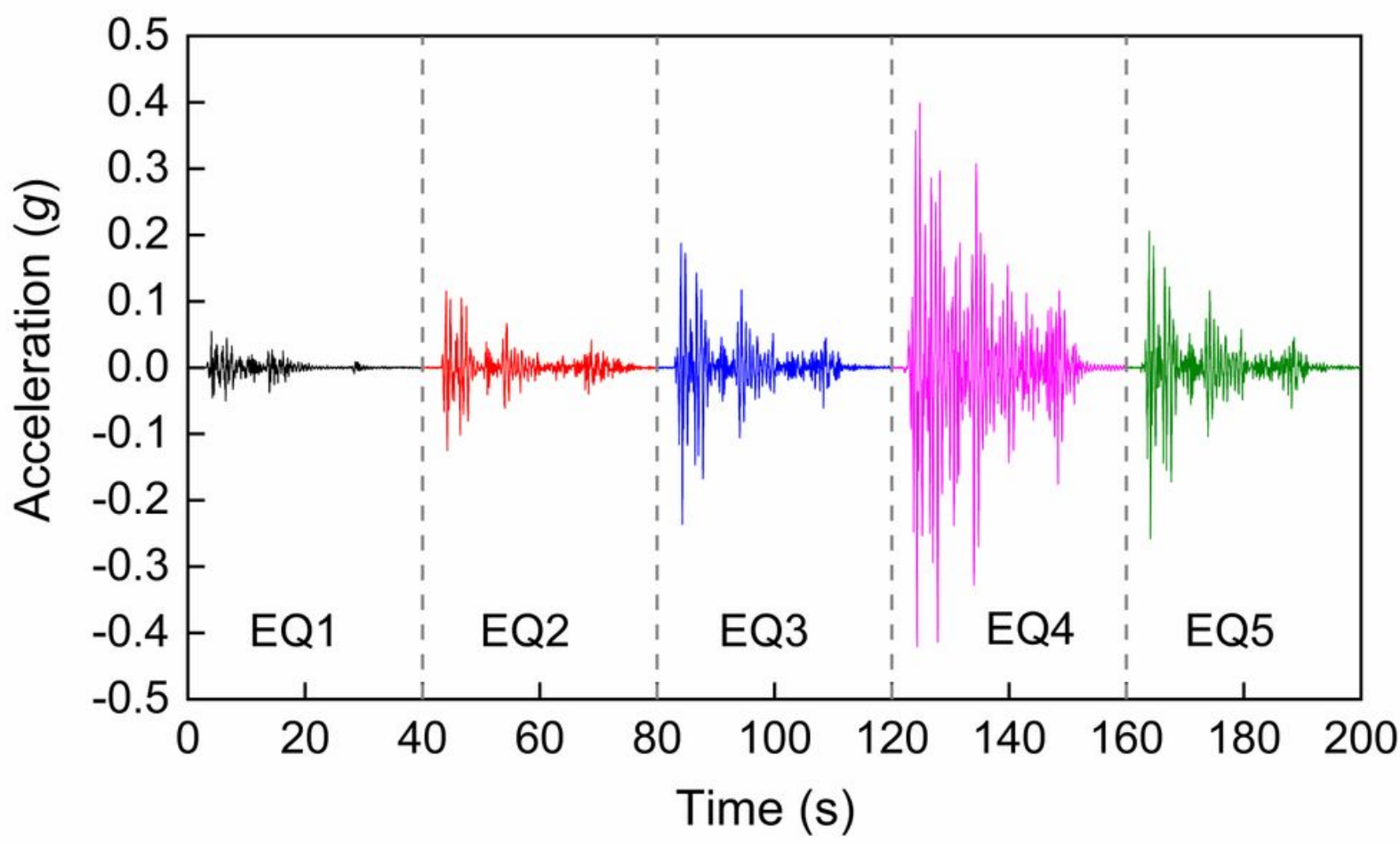

Figure 2

Time histories of input motions at instrument BA-0 

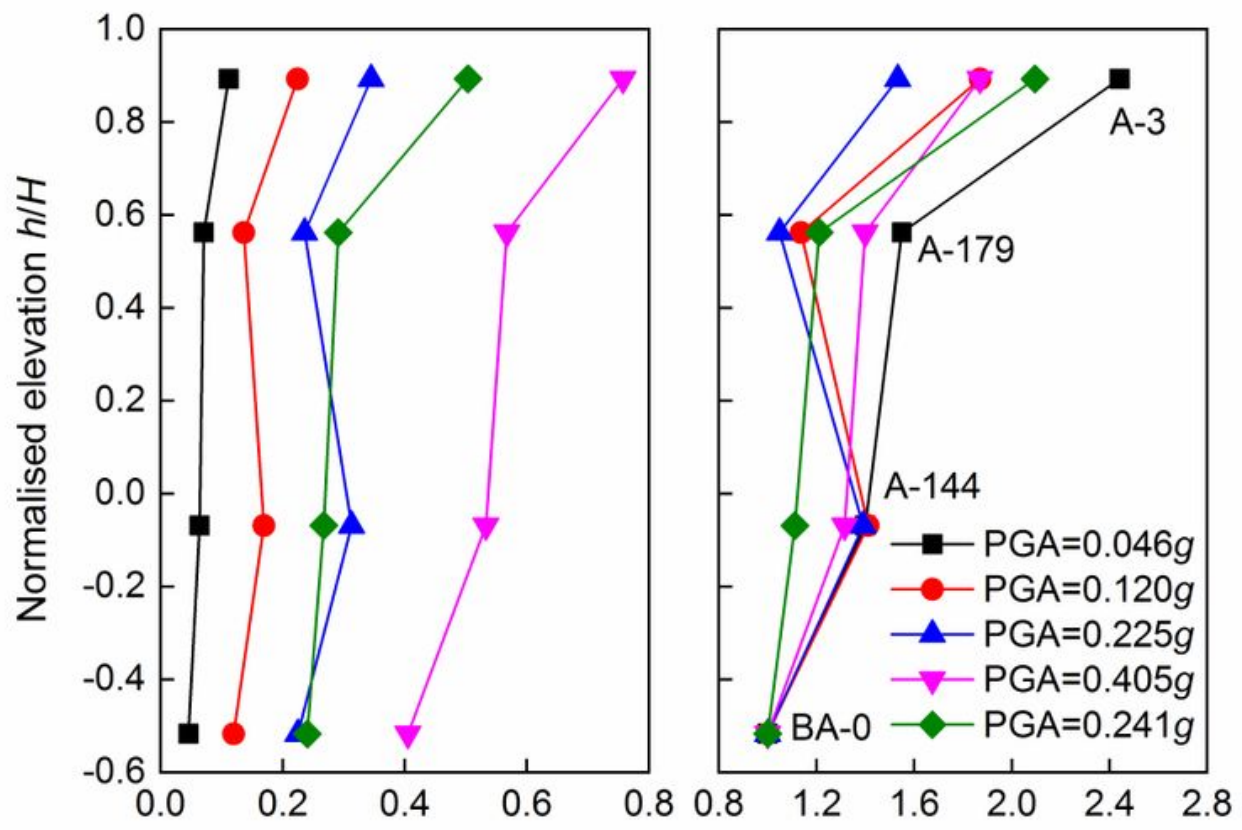

(a) Maximum acceleration $(g)$ PGA amplification factor $S_{p}$
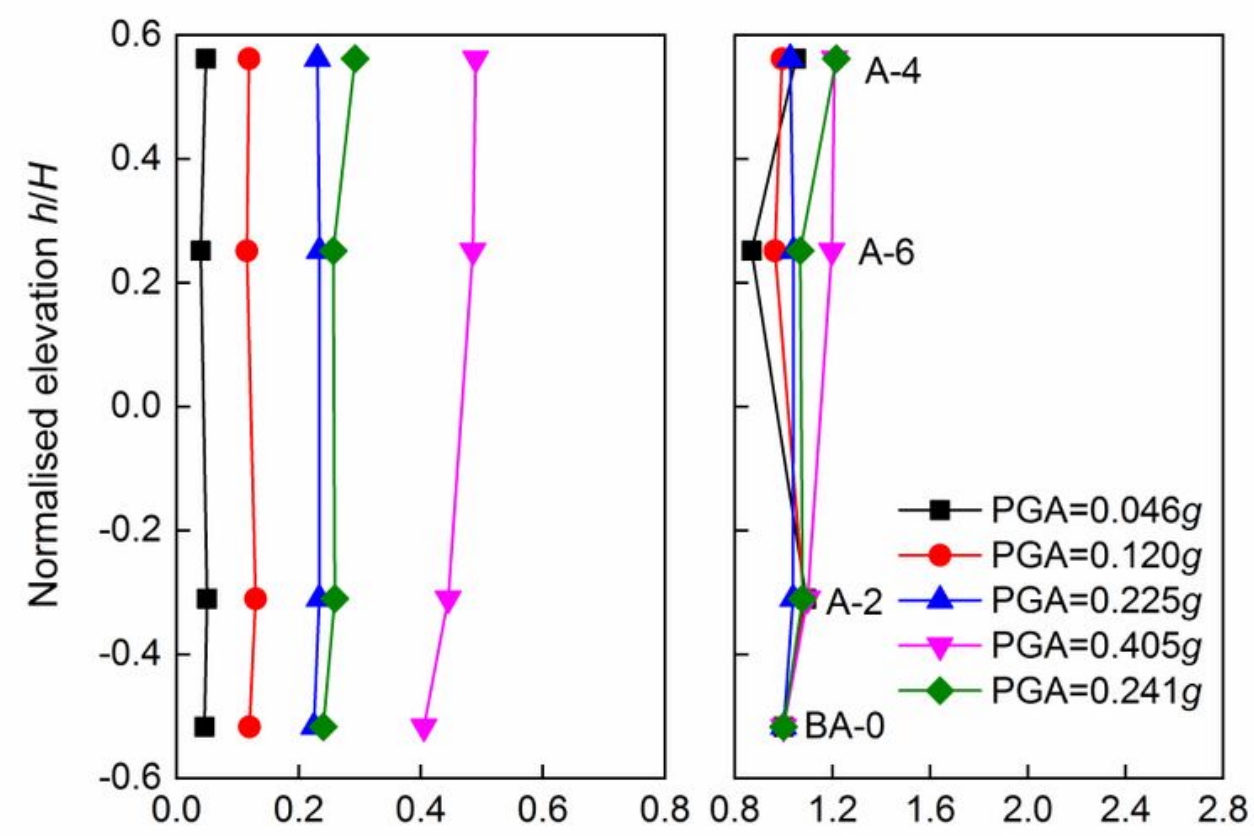

(b) Maximum acceleration $(g)$ PGA amplification factor $S_{p}$

Figure 3

Maximum acceleration distributions along the normalised slope elevation in the $1 \#$ model in centrifuge tests. a Deposit surface. b Bedrock surface 


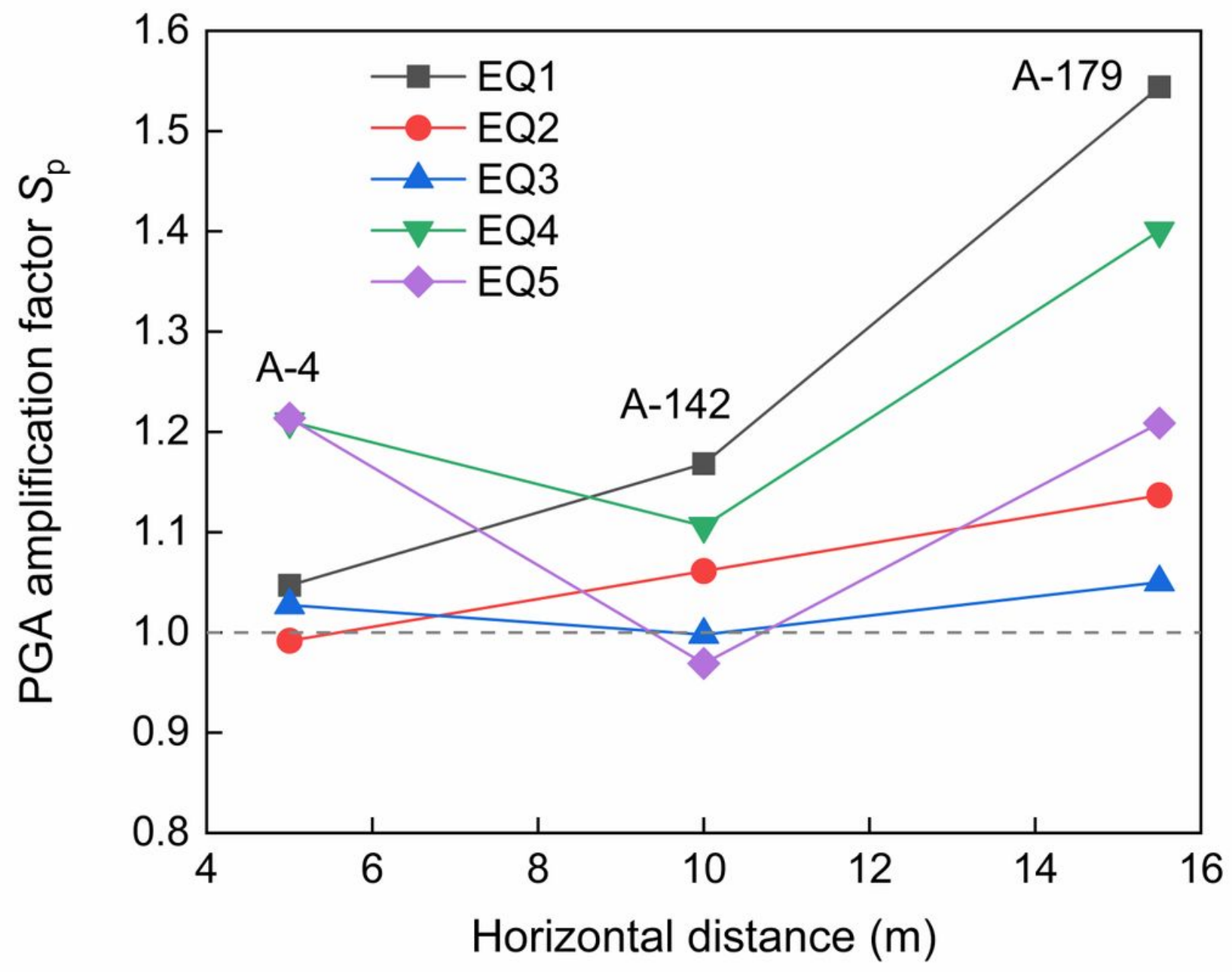

Figure 4

The horizontal acceleration amplification factor distribution from the inside of the slope to its surface at a height of $15.8 \mathrm{~m}$ in the $1 \#$ model in centrifuge tests 


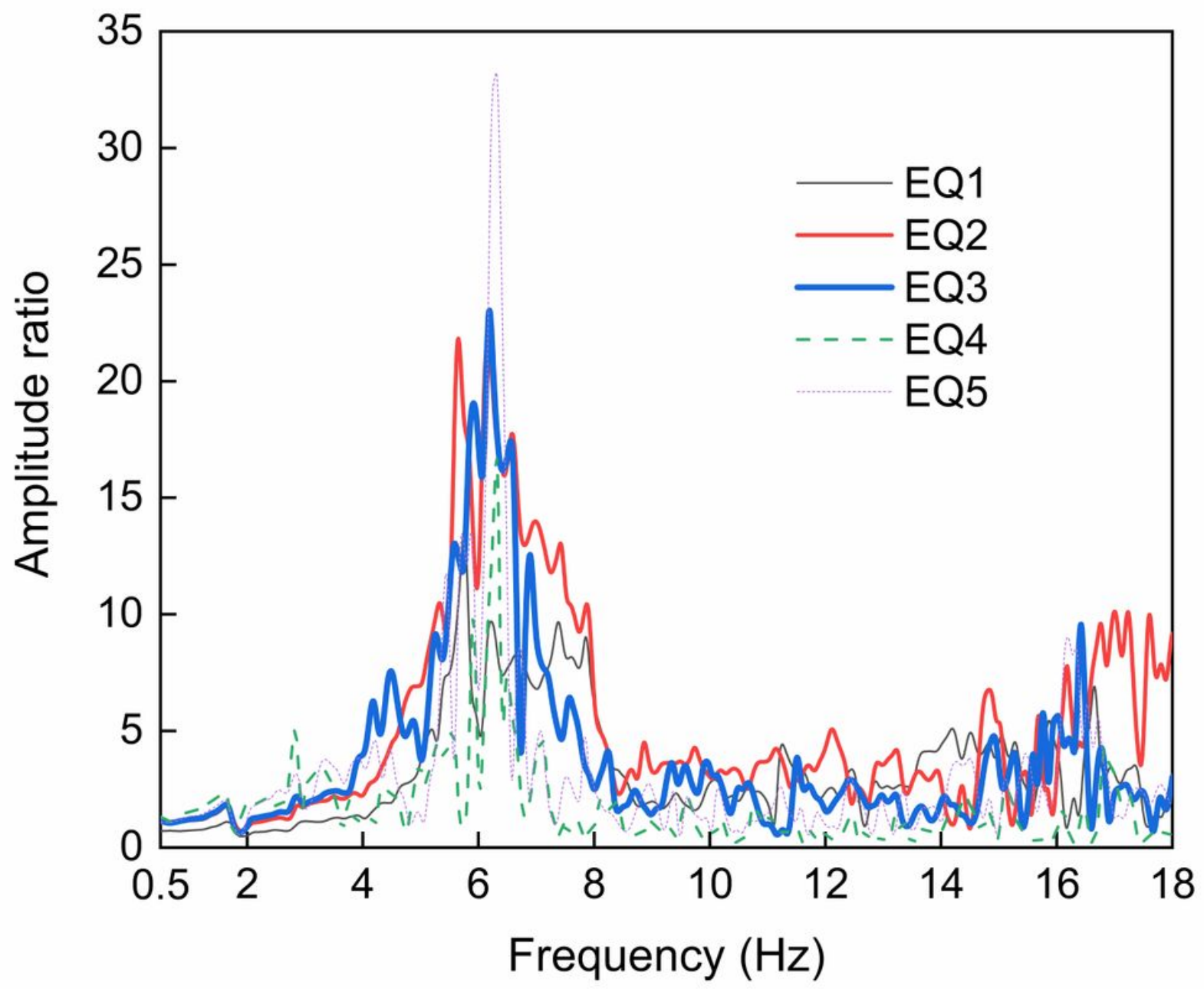

Figure 5

The amplitude ratios of the transfer function of the acceleration measured at A-3(slope crest) and A-0 (bottom of the model box) in the 1 \#model during centrifuge testing 

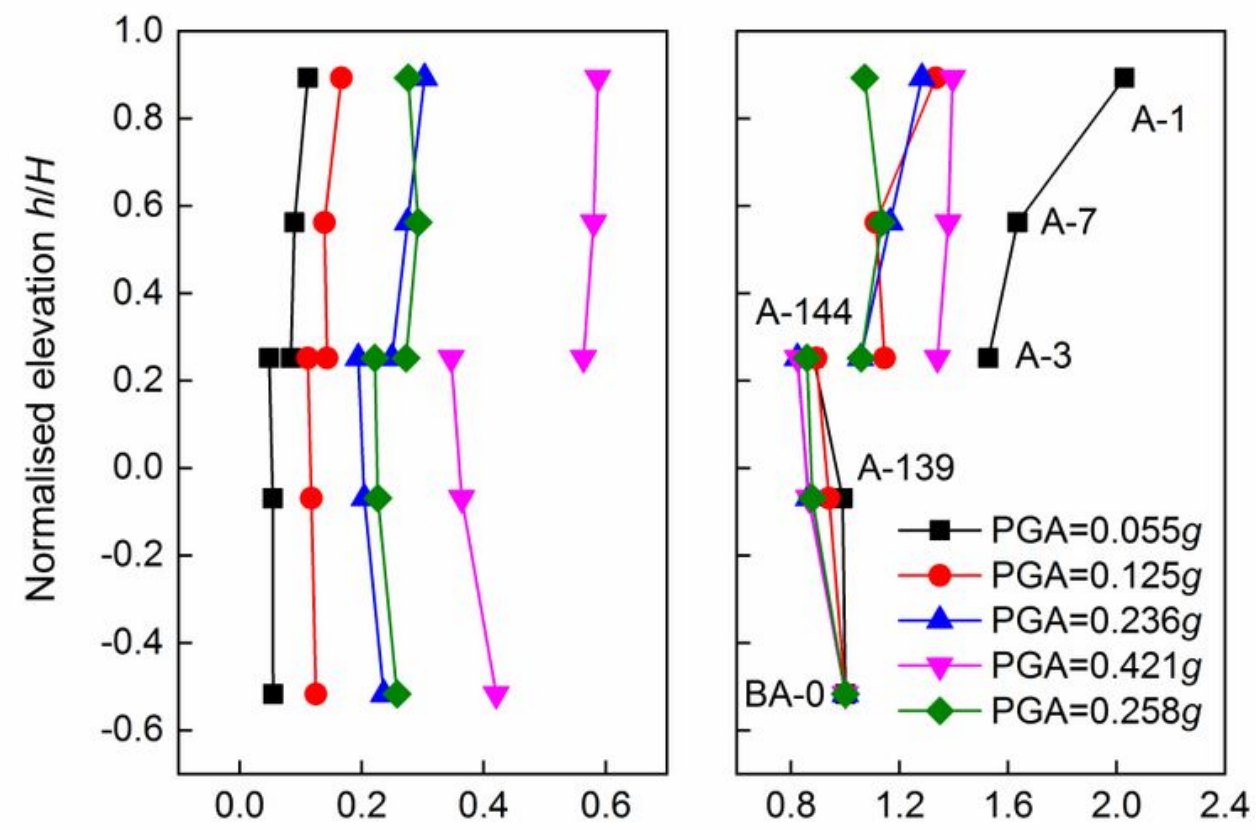

(a) Maximum acceleration $(g) \quad$ PGA amplification factor $S_{p}$
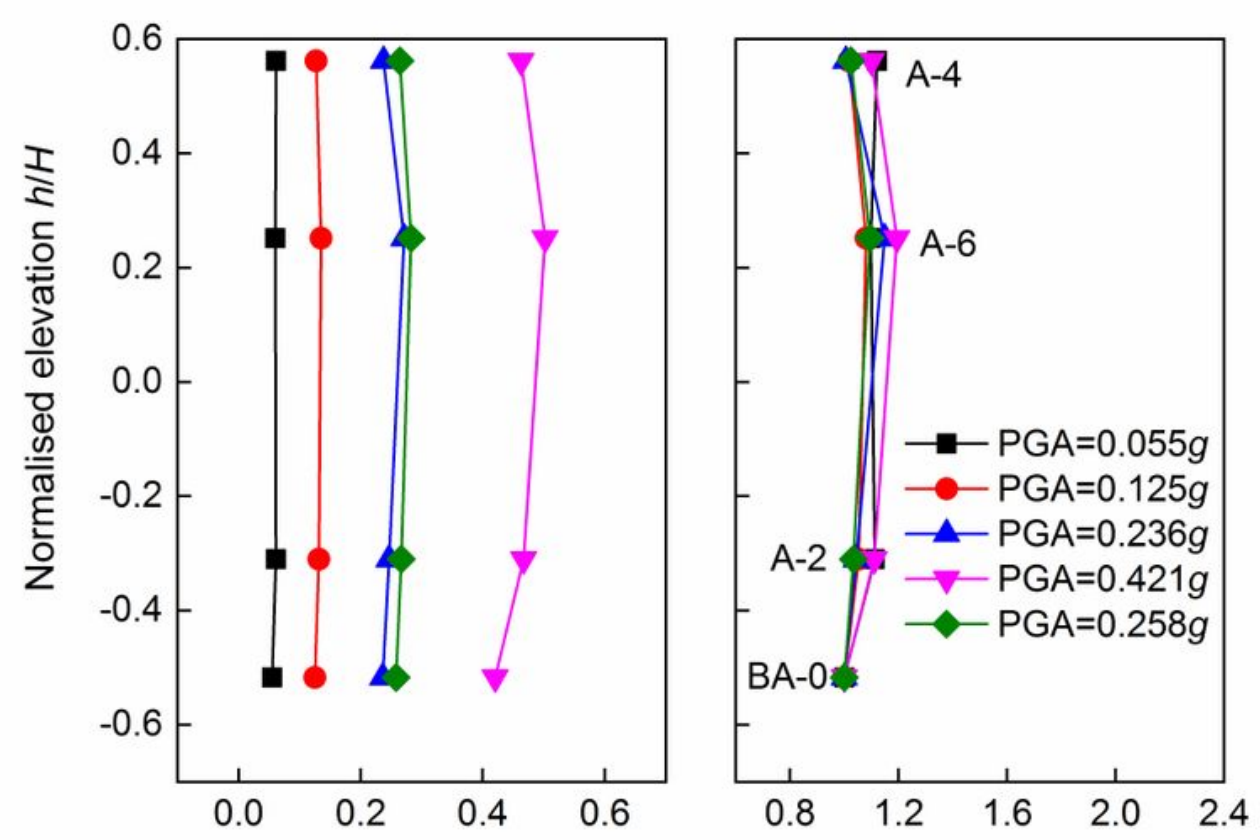

(b) Maximum acceleration $(g) \quad$ PGA amplification factor $S_{\mathrm{p}}$

Figure 6

Maximum acceleration distributions along the normalised slope elevation in the $2 \#$ model in centrifuge tests. a Deposit surface. b Bedrock surface 


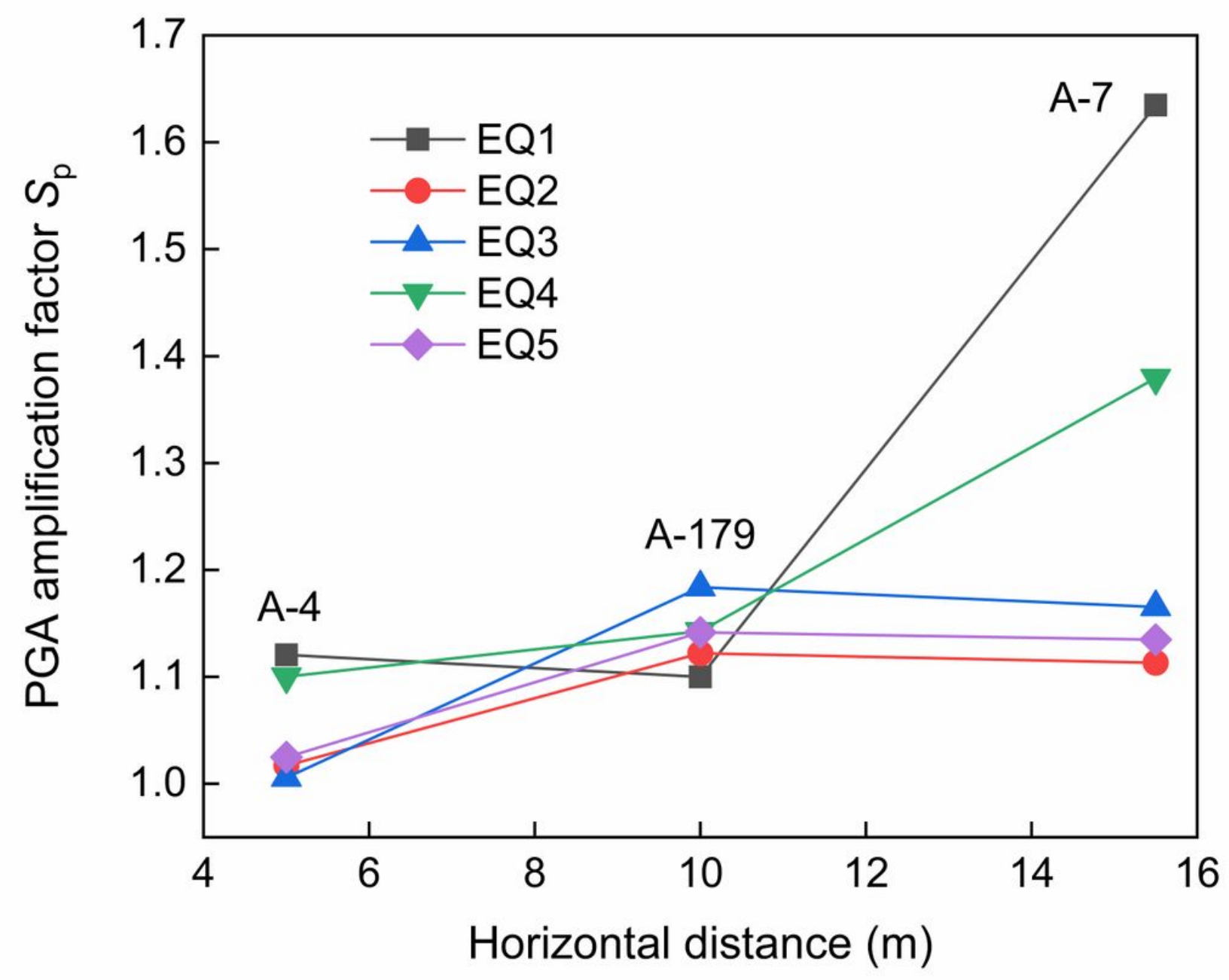

Figure 7

The horizontal acceleration amplification factor distribution from the inside of the slope to the surface of the slope at a height of $15.8 \mathrm{~m}$ in the $2 \#$ model in centrifuge tests 


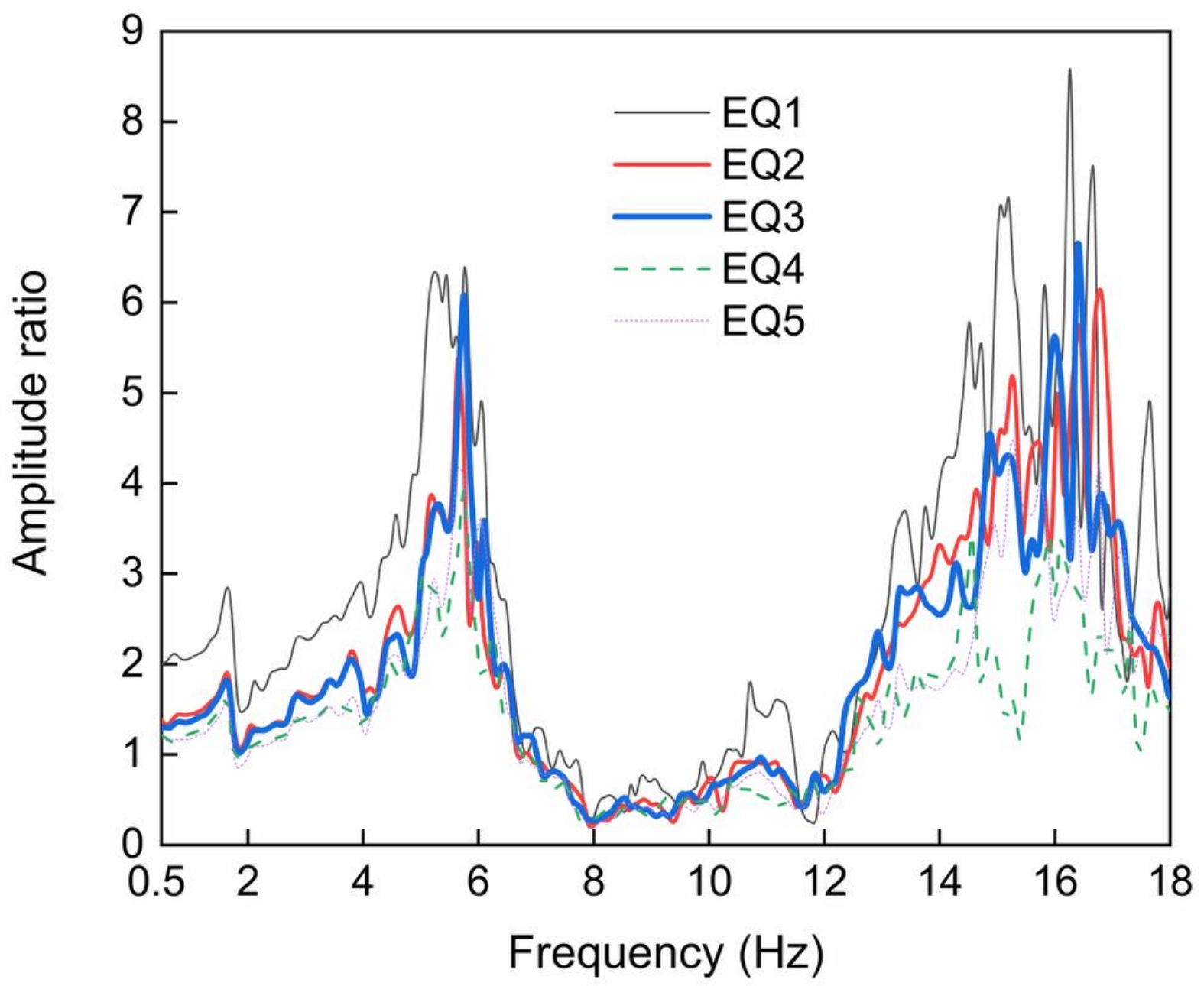

Figure 8

The amplitude ratios of the transfer function of the acceleration measured at A- 1 (slope crest) and A-0 (bottom of the model box) in the 2\#model during centrifuge testing 

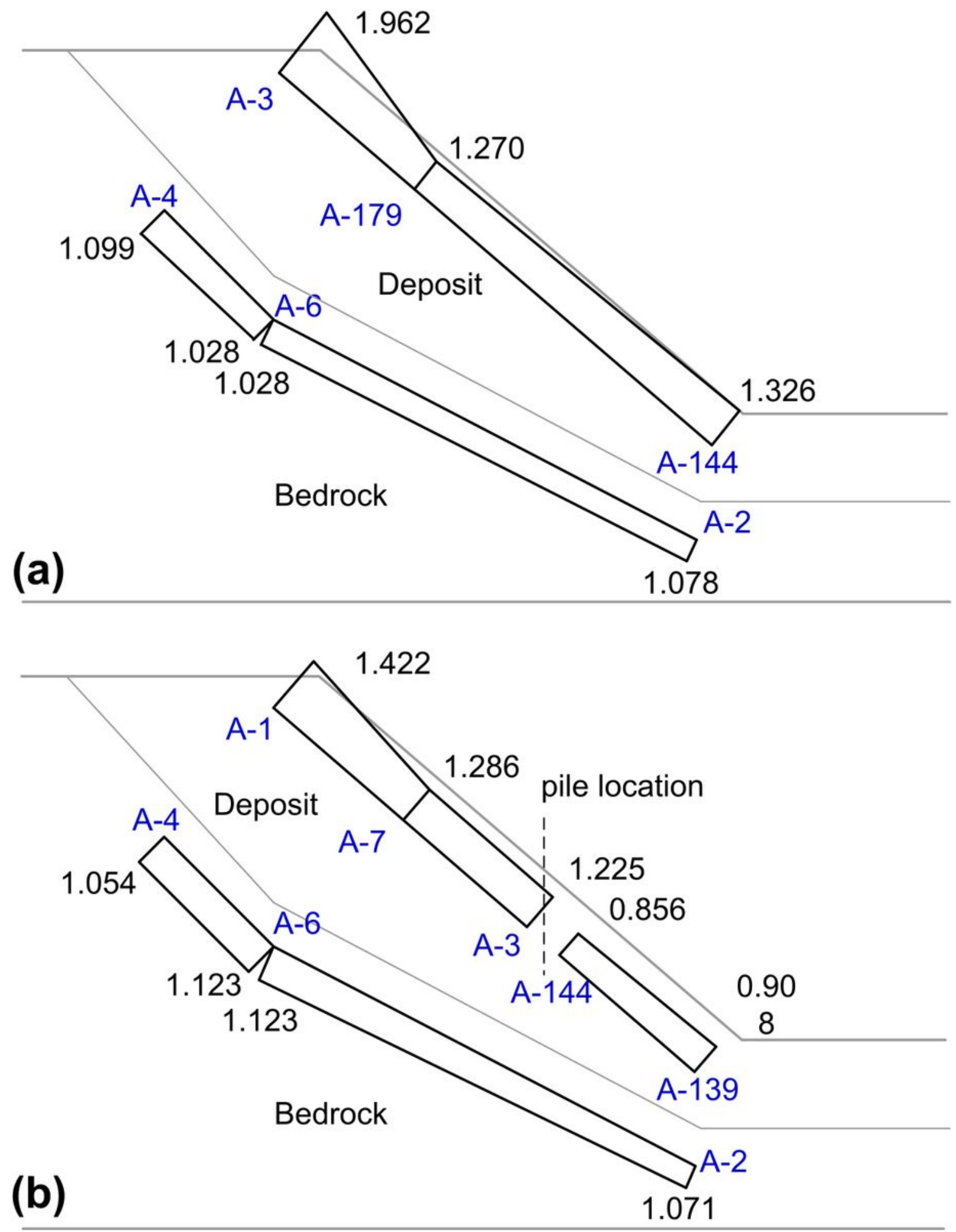

Figure 9

Average horizontal PGA amplification factor distribution in the underlying bedrock deposit slope in centrifuge tests. a 1\#model. b 2\#model 


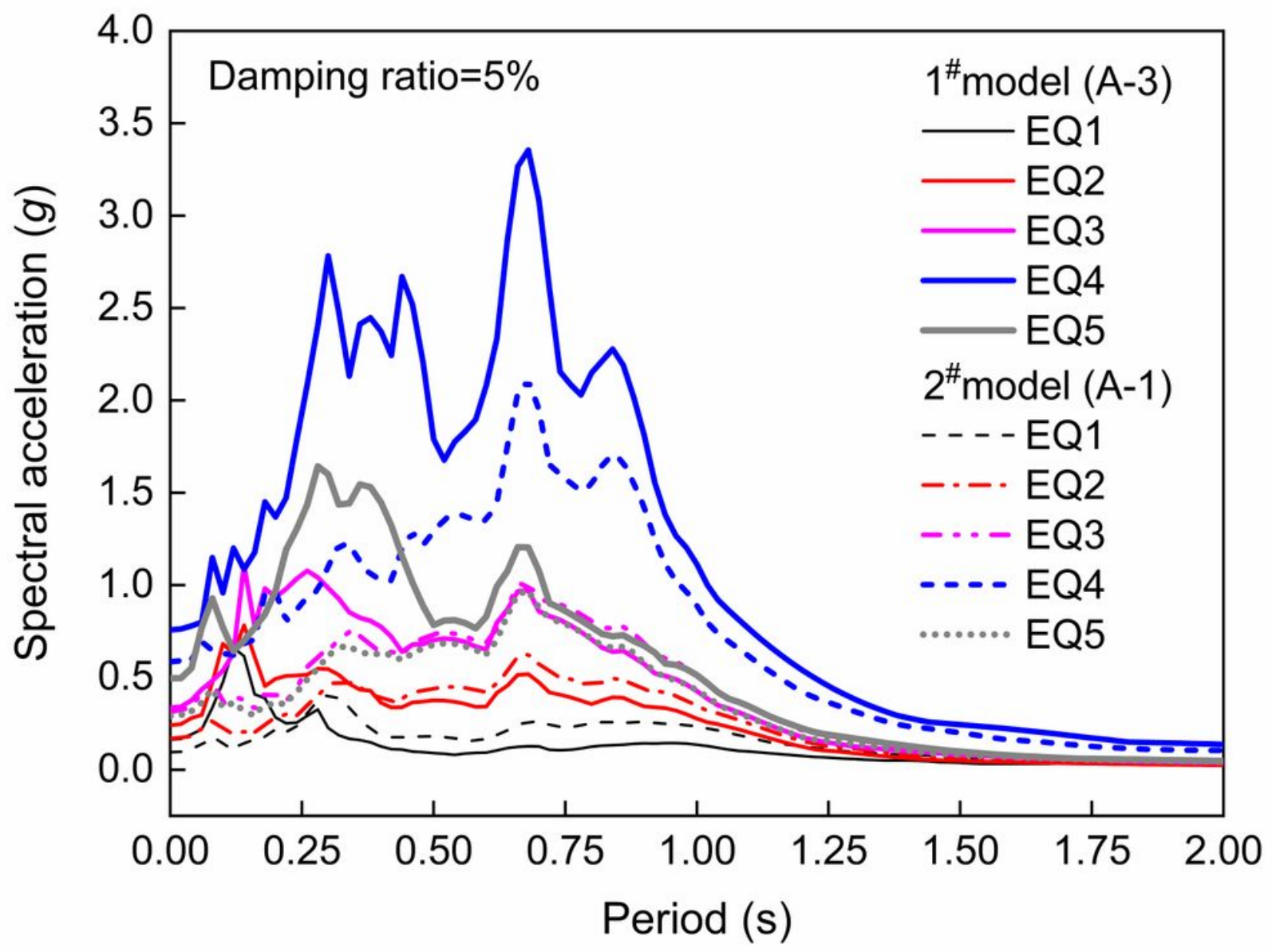

Figure 10

Response spectral accelerations of the slope crest ( $5 \%$ damping ratio) 

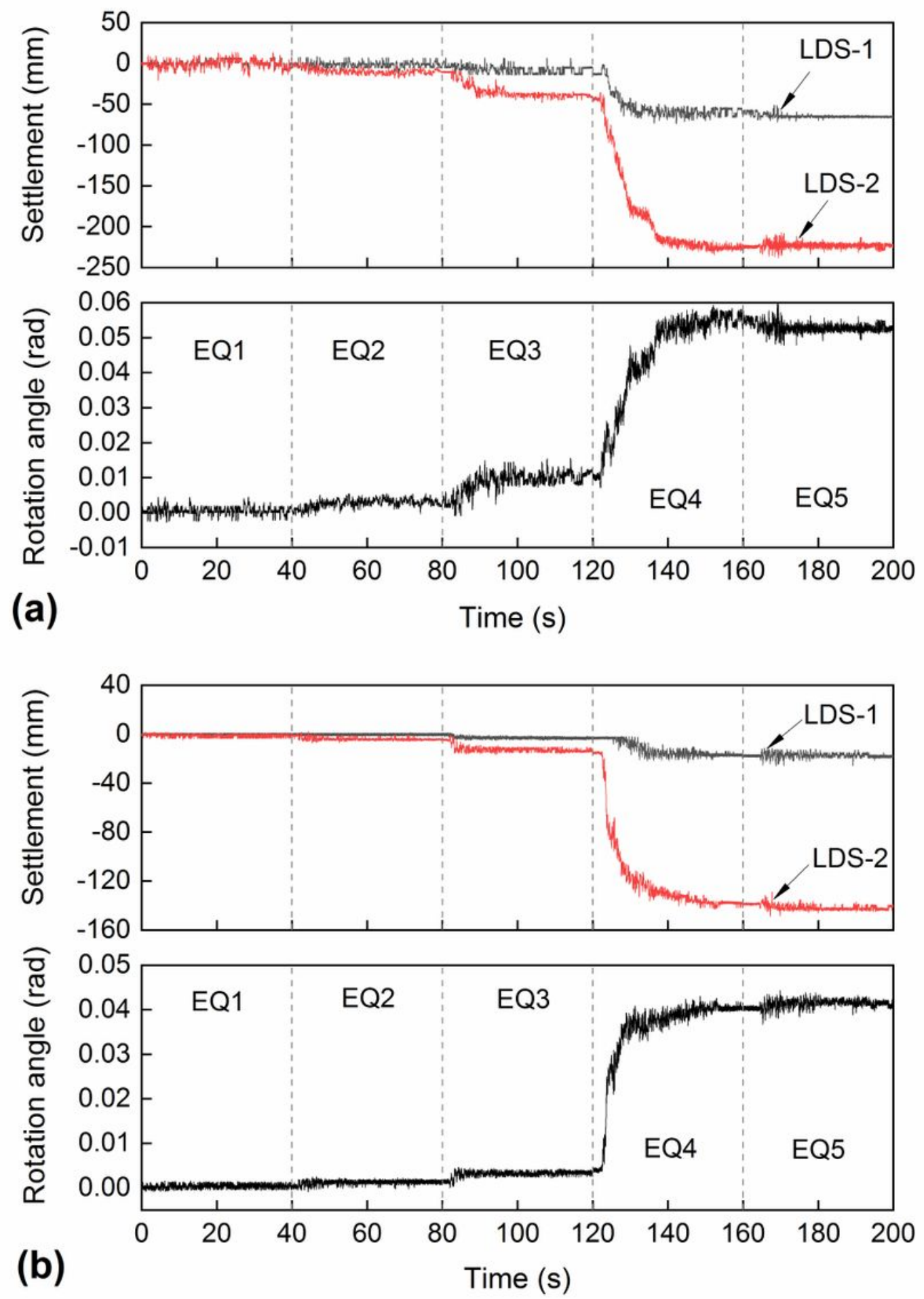

Figure 11

Crest settlements and crest rotation angle under seismic excitation. a 1\#model. b 2\#model 


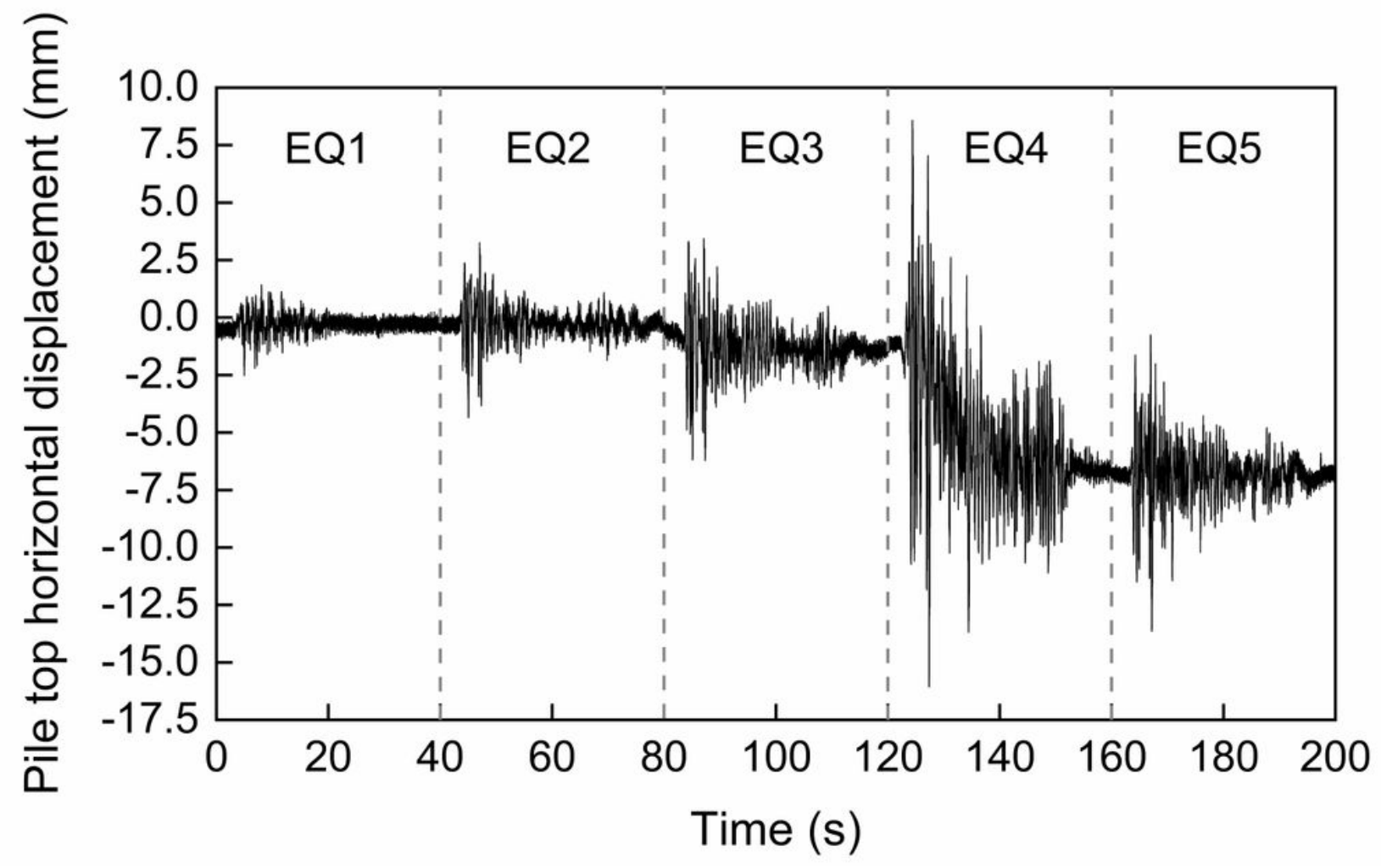

Figure 12

Pile top horizontal displacement under seismic excitations in the 2\#model 


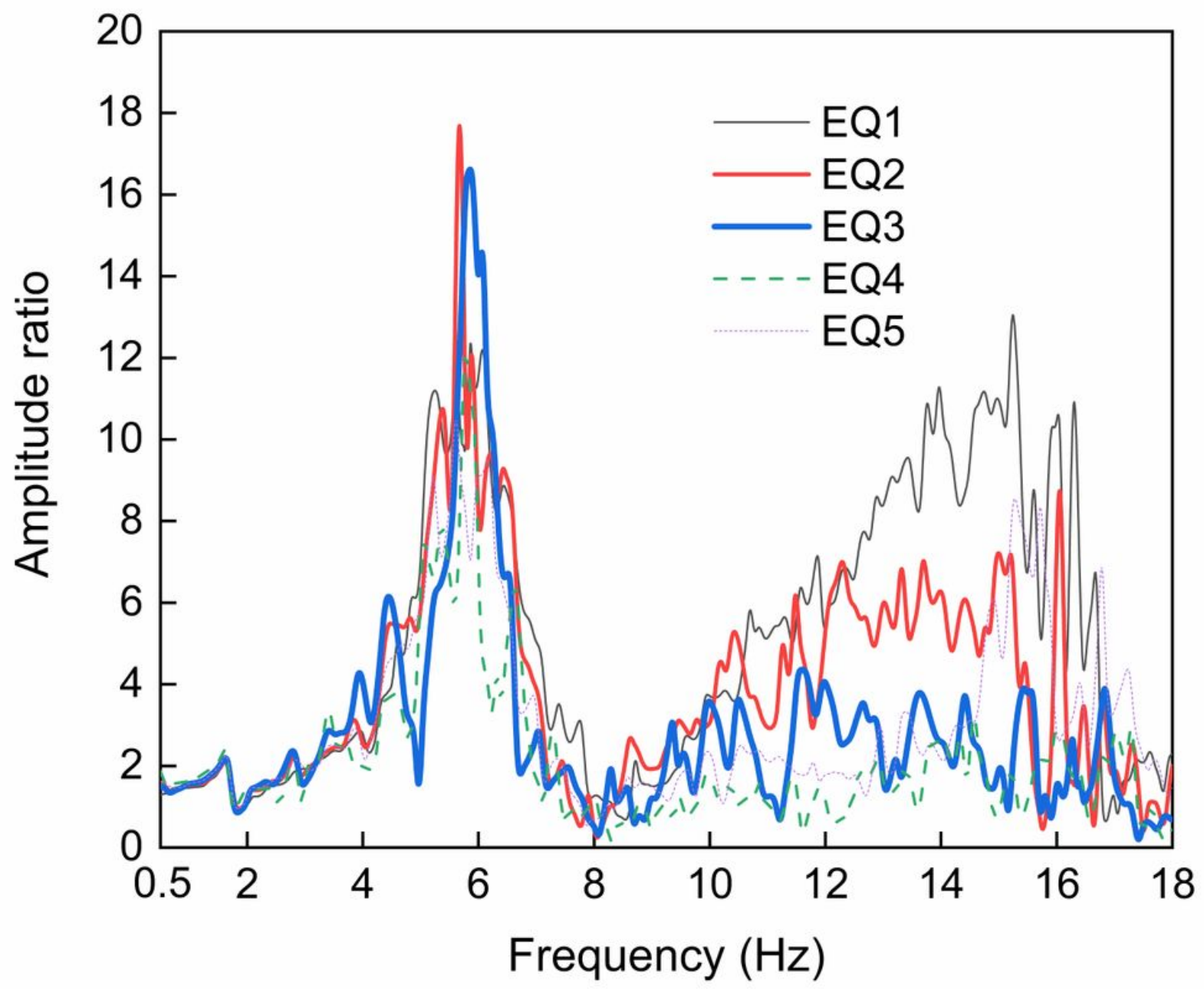

Figure 13

The amplitude ratios of the transfer function of the acceleration measured at A-1079 (pile top) and A-0 (bottom of the model box) in the 2\#model during centrifuge testing 


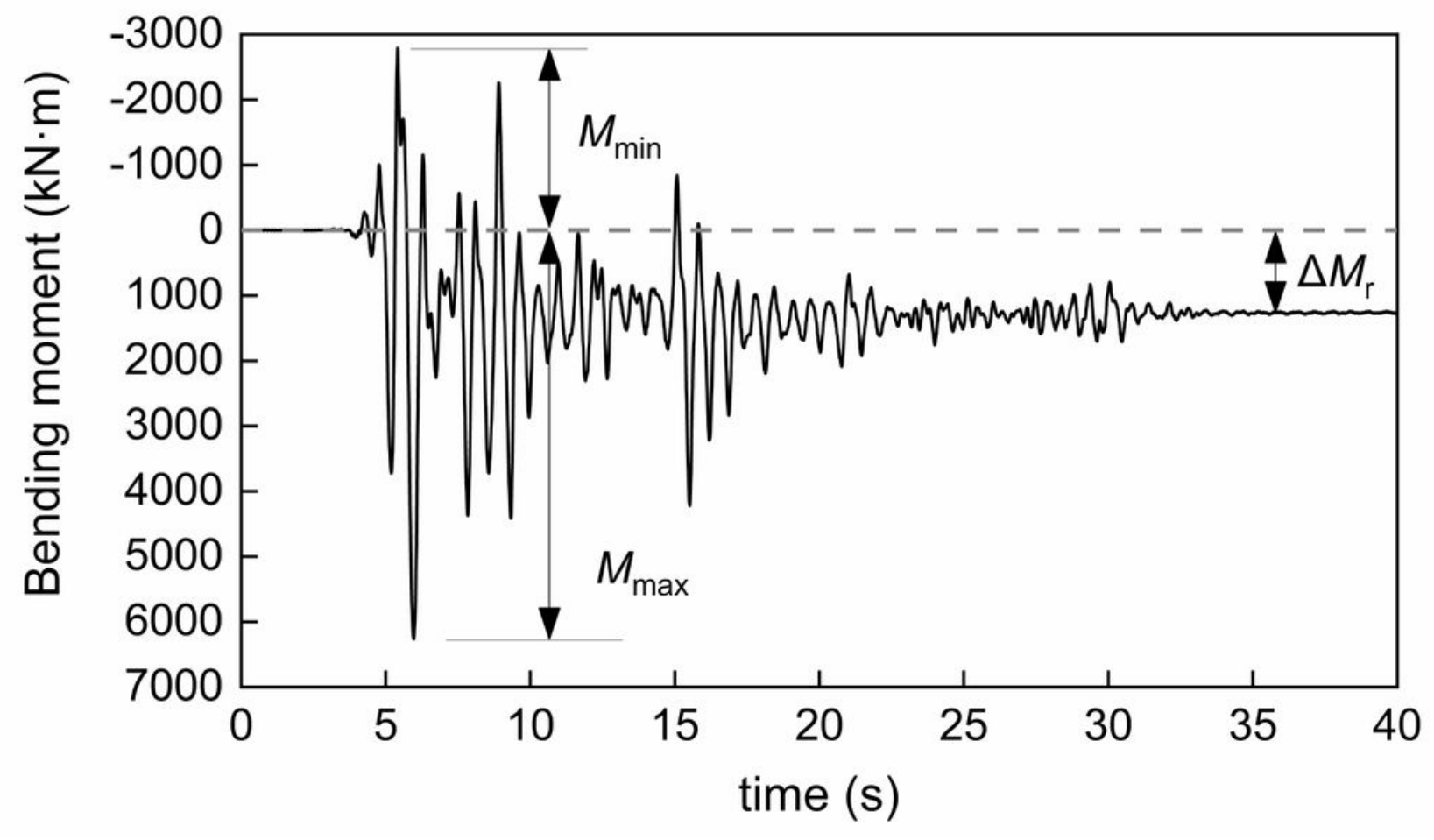

Figure 14

Typical response time-history curves of bending moments in the centrifuge test (EQ4, S3) 

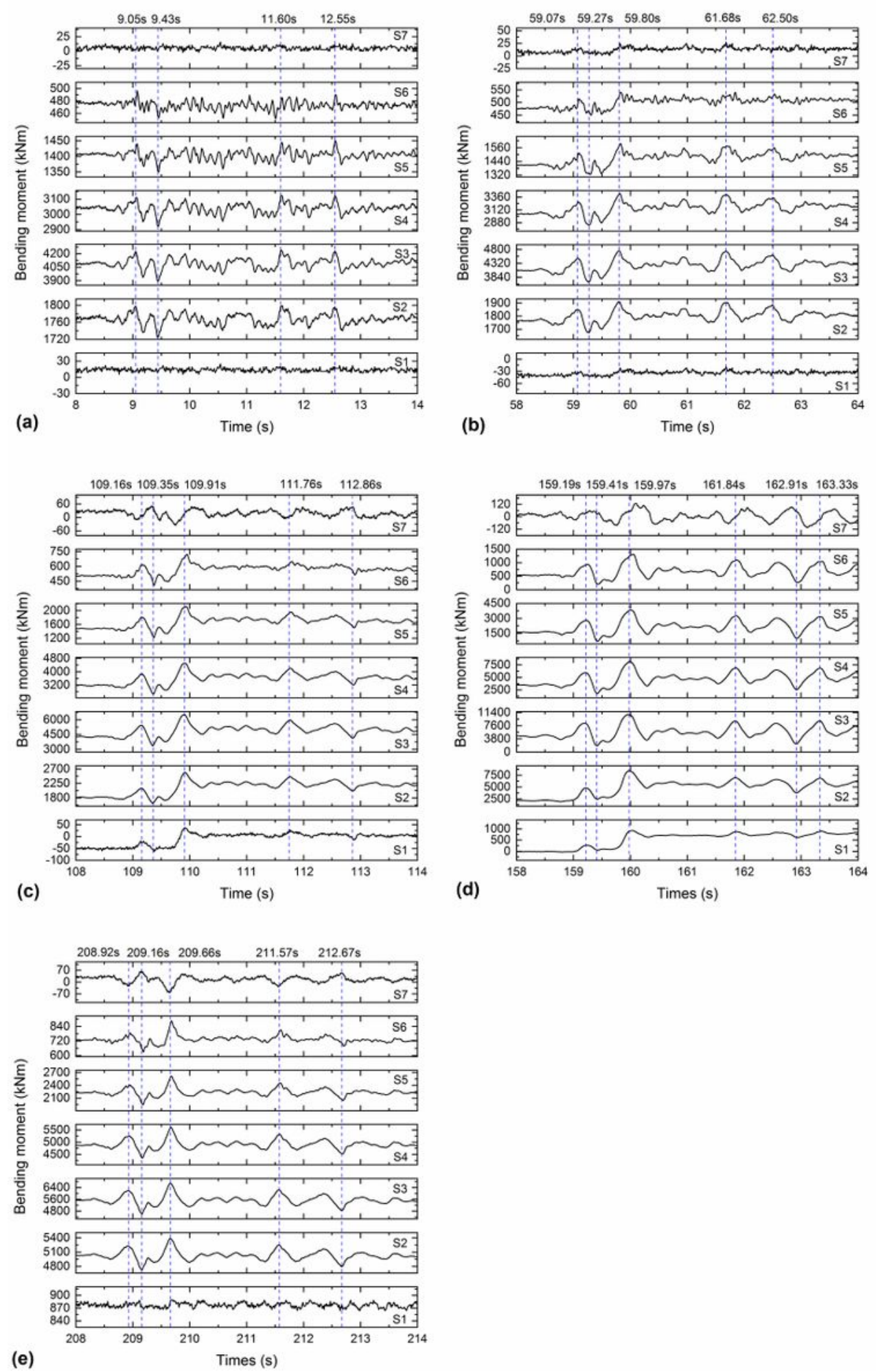

\section{Figure 15}

Time-history curves of bending moments in centrifuge tests. a EQ1. b EQ2. c EQ3. d EQ4. e EQ5 

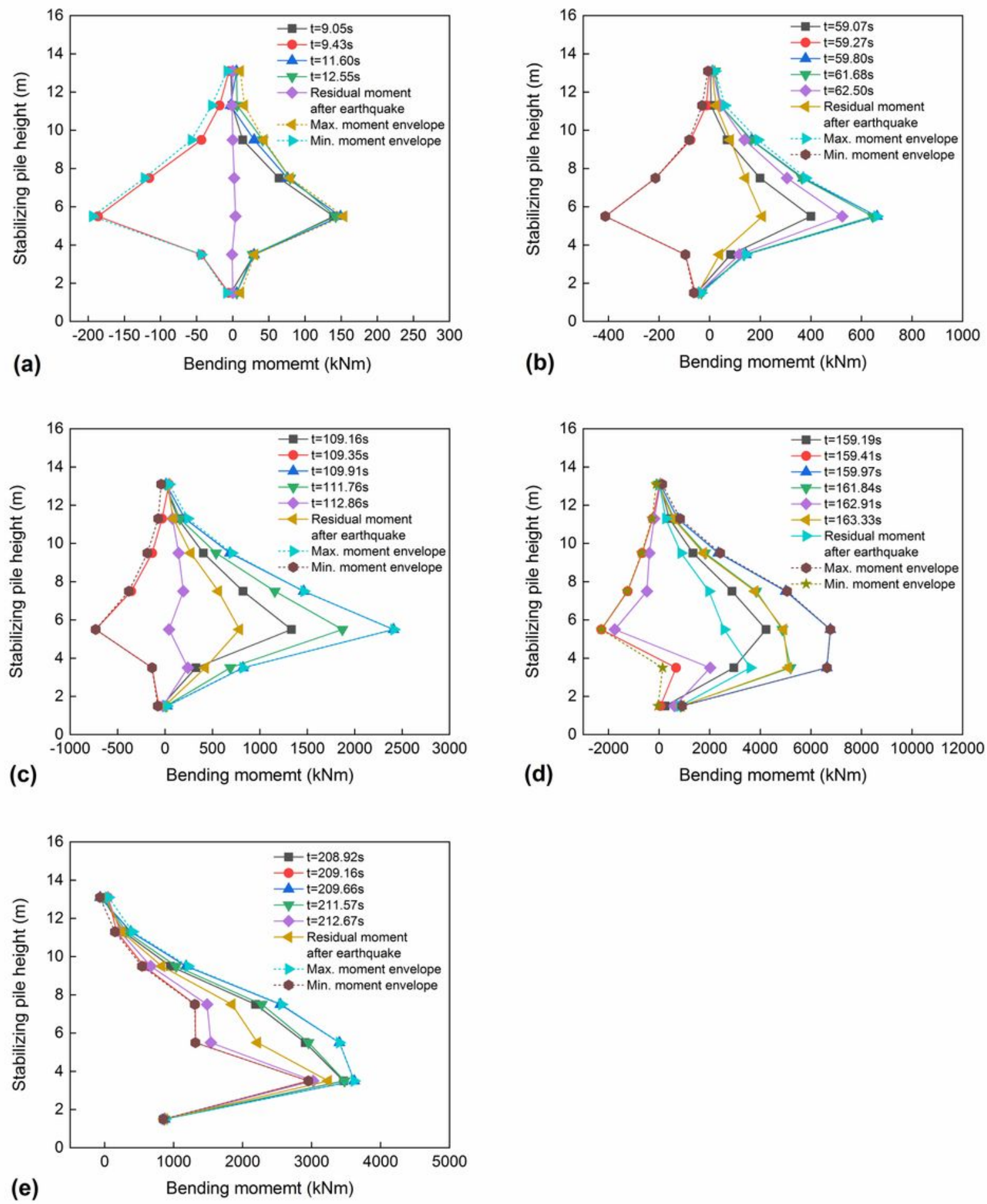

\section{Figure 16}

Maximum and minimum bending moment envelopes, residual bending moment after an earthquake, and the dynamic bending moment on a stabilising pile. a EQ1. b EQ2. c EQ3. d EQ4. e EQ5 


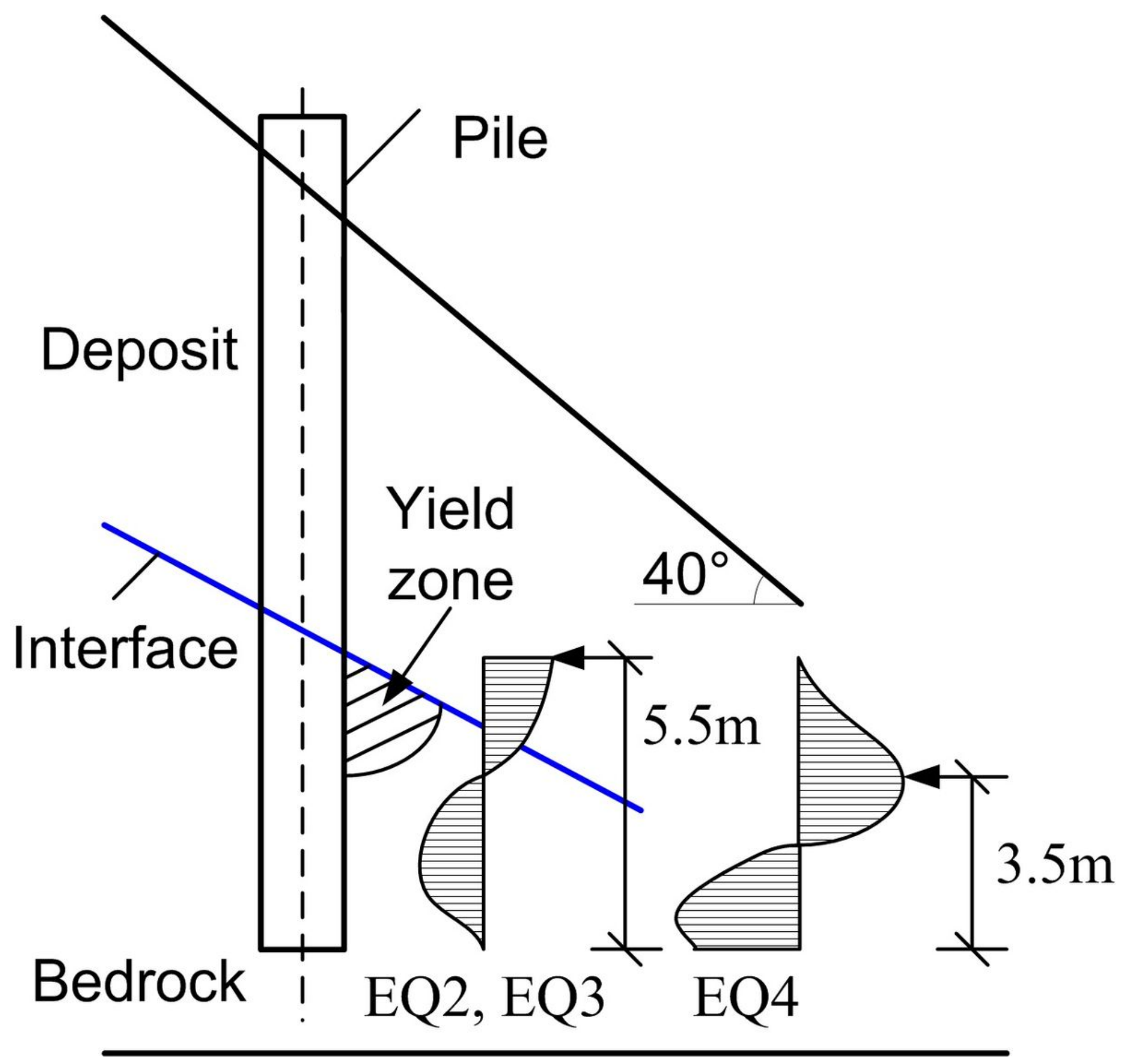

Figure 17

Schematic representation of the resistance exerted by a stabilising pile in the bedrock 


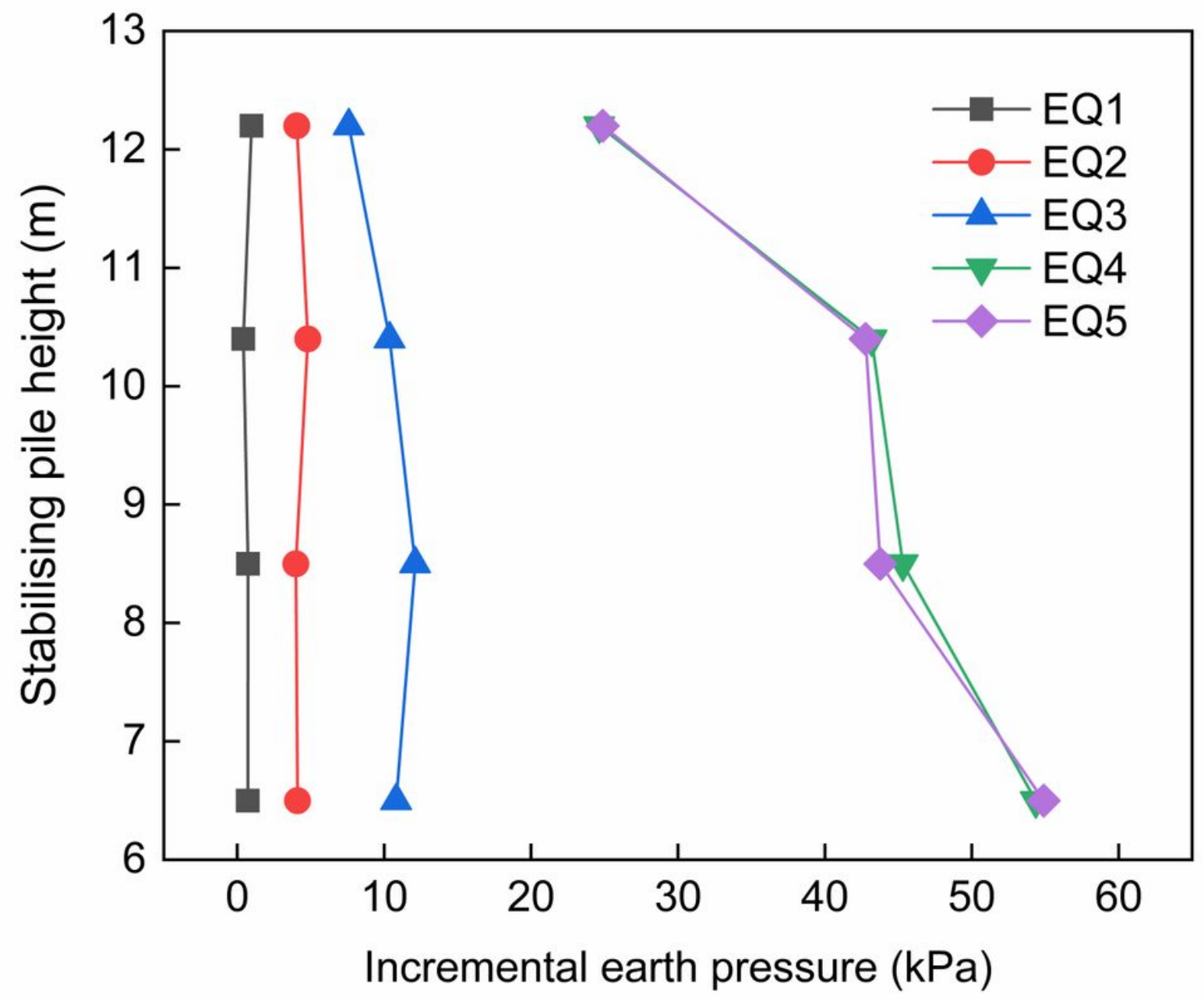

Figure 18

Incremental earth pressure measured by earth pressure cell after each shaking event 

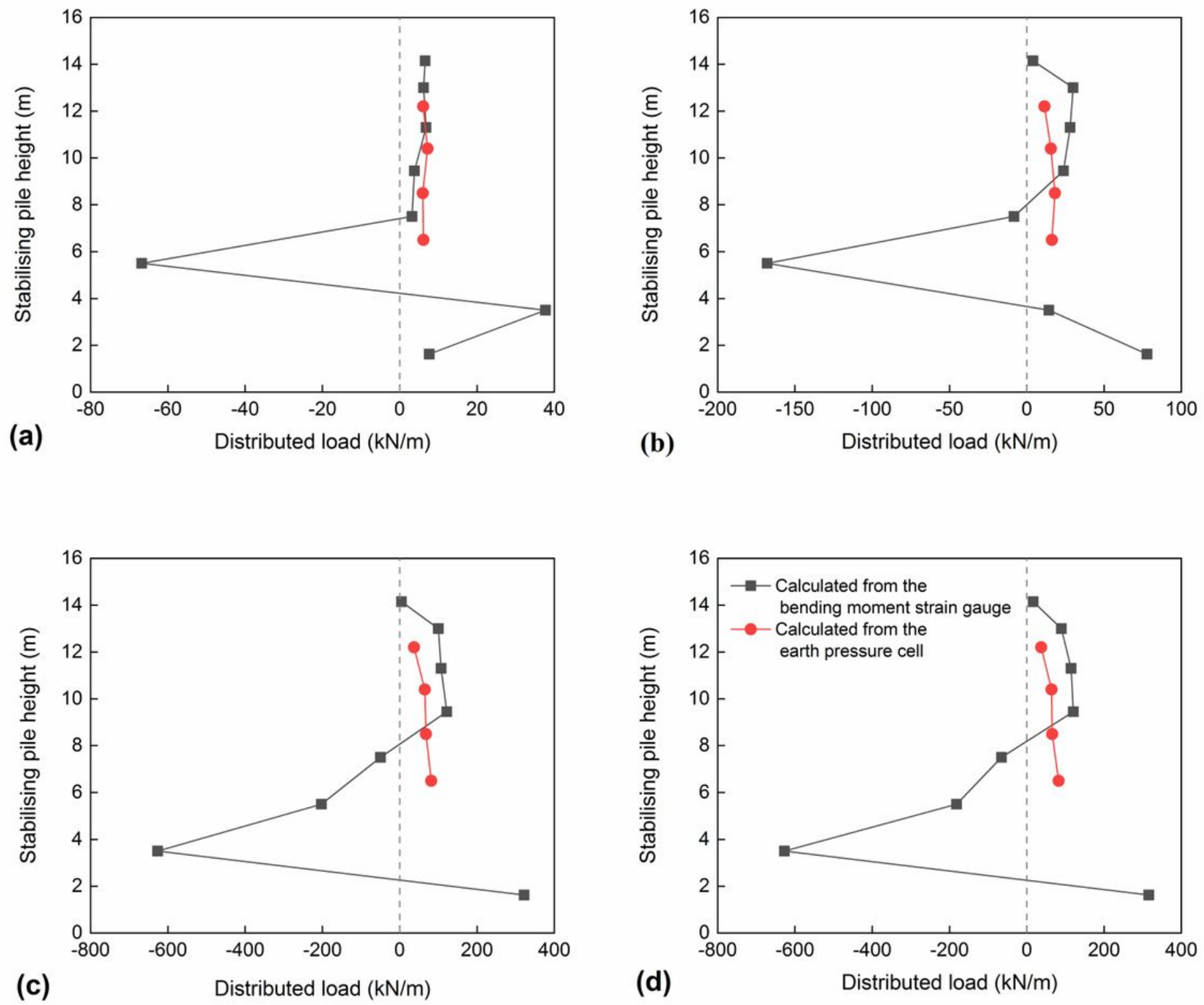

Figure 19

Comparison of distributed load increment obtained by moment strain gauge and earth pressure cell on a stabilising pile after each shaking event. a EQ2. b EQ3. c EQ4. d EQ5 


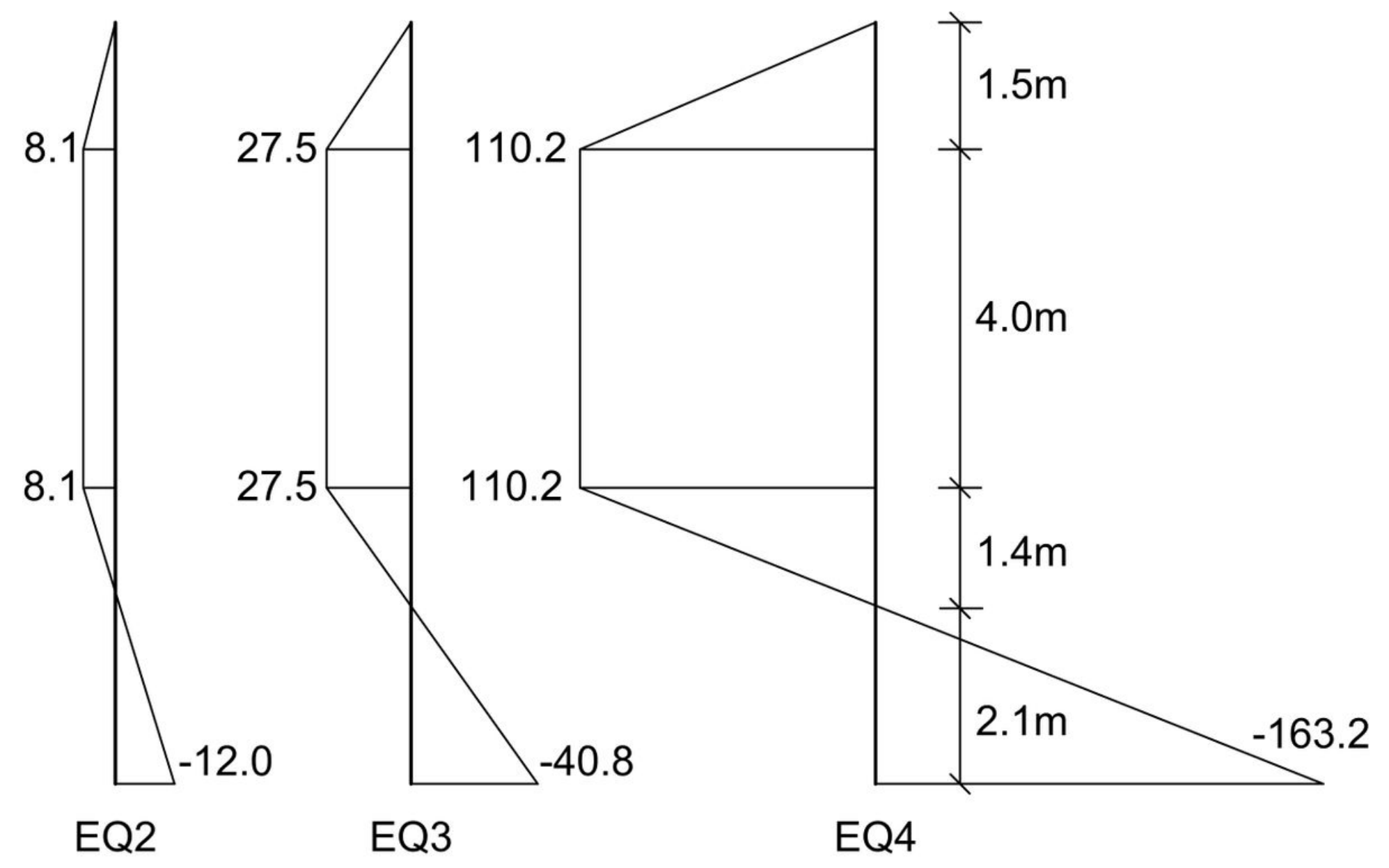

Figure 20

Simplified distributed load increment above the slip surface after each shaking event (unit: $\mathrm{kN} / \mathrm{m}$ ) 


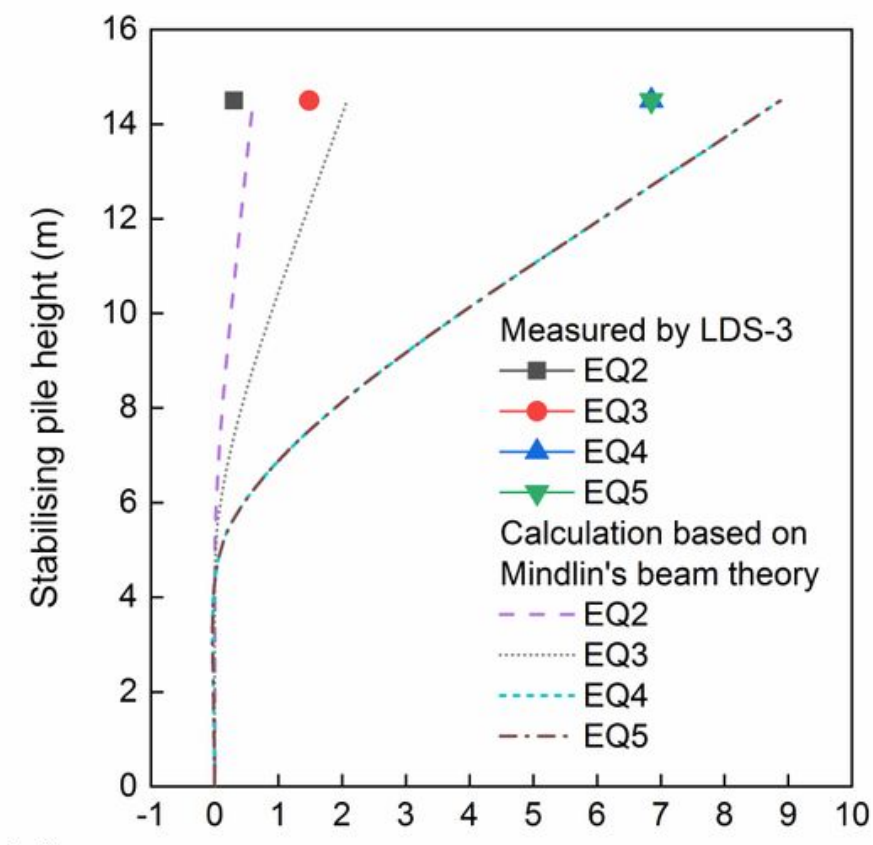

(a)

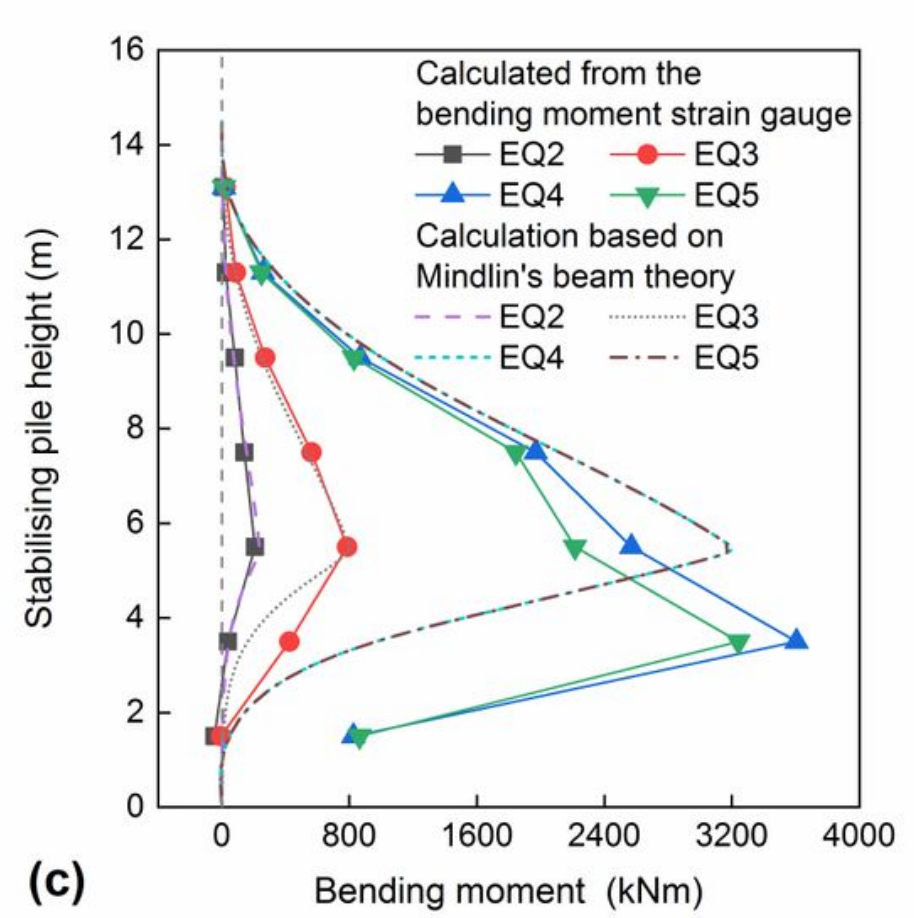

(c)

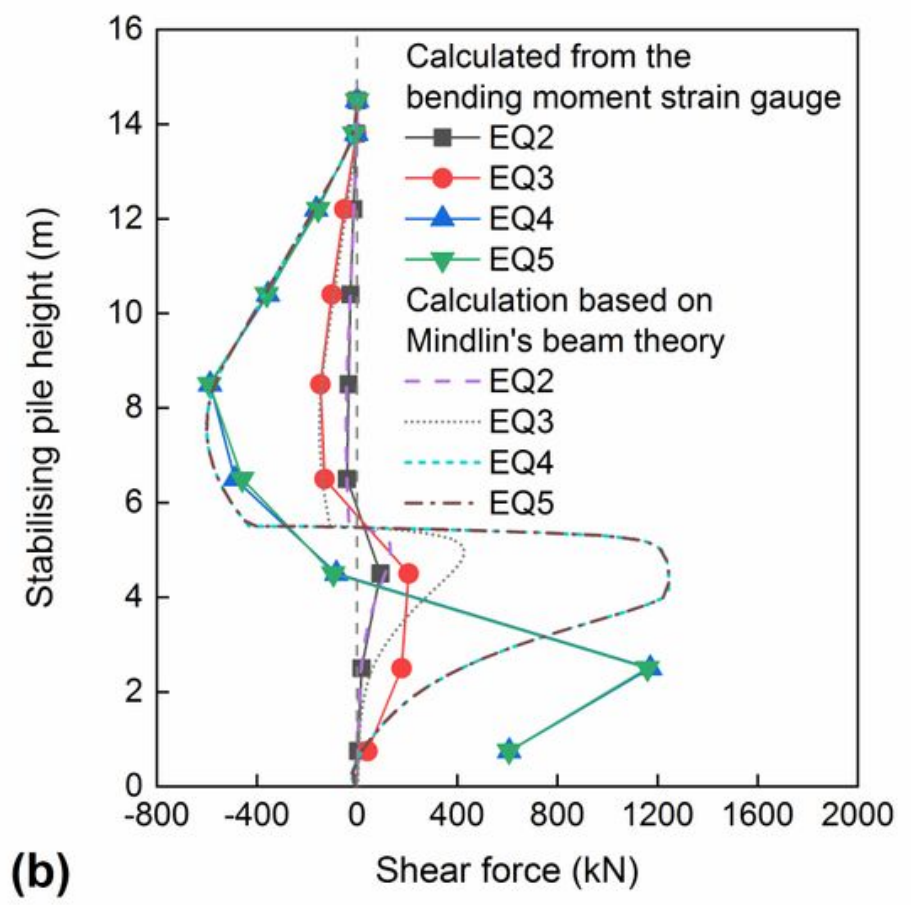

(b)

Shear force $(\mathrm{kN})$

\section{Figure 21}

Comparison of the calculated results after test-measurement conversion and the calculated results based on Mindlin beam theory for a stabilising pile after each shaking event. a Horizontal displacement. b Shear force. c Bending moment 